\title{
The role of developing open commercial urban spaces in improving human behavior (Case Study - Development of the Main Open Market in Minia City)
}

\author{
Mohanad Mohamed Al-Agamy a*, Osama Helmy Mohamed a , Abd El-Rahman Mohamed Tony ${ }^{\text {a }}$ \\ a: Architecture department, Faculty of Engineering, Minia University, Egypt, 61519
}

* Corresponding author: Prof. Mohanad Mohamed Al-Agamy, E-mail: elagami5@yahoo.com

\begin{abstract}
Urban design and planning processes aim to create an environment that is consistent with the needs and behaviors of its users. Studies have shown that urban spaces that do not meet the requirements of the users; Lead to negative impacts (environmental / behavioral / social / cultural / ...) on these individuals; Which may lead to abandoning these urban spaces or trying to make adjustments to them in line with their needs, or giving them new behaviors that help them adapt to those spaces. The recent research provides an explanation of the urban spaces that are the subject of the research (definition and objectives) and the design determinants, then the research moves to present the human needs within the urban spaces and the mutual influence between the human being and the urban spaces. The research explains the nature of open markets as one of the most important urban spaces that people deal with on a daily basis, its urban characteristics, the foundations of its design and types, with a presentation of some experiences from different countries for market development projects, with the aim of improving and advancing them and the impact of this development on human behavior. The paper deals with the issue of the spread of open markets, which represent part of the urban spaces that affect human behavior. Indeed, the presence of activities in the spaces that are not suitable for them leads to an imbalance in the surrounding urban environment. The research presents a study of the main open market in Minya (Habashi market) and provides solutions to upgrade it by making use of previous experiences. The research ends with a set of general findings and recommendations through which some realistic solutions to the problems of open markets can be extracted to work on improving human behavior.
\end{abstract}

Keywords: Urban spaces; Open markets; Human behavior; Commercial spaces; Random markets

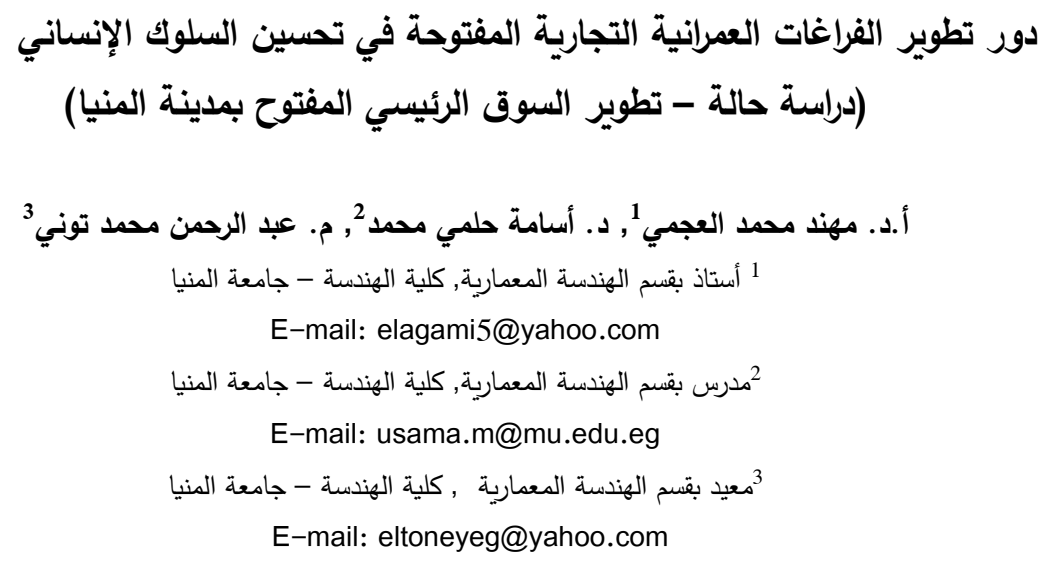


تهدف عمليات التصـيم والتخطيط العمراني إلى تكوين بيئة تتماشى مـع احتياجـات وسلوكيات المستخدمين لها، وقد أوضـت الدراسات أن

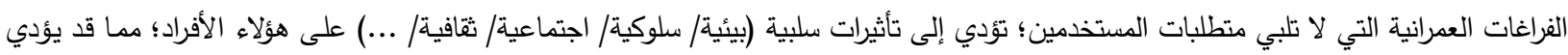

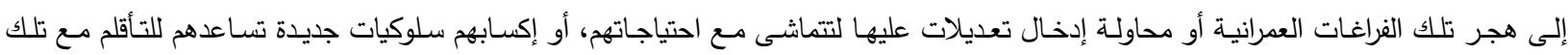

تقدم الورقـة البحثيـة شـرحاً للفراغـات العمرانيـة موضـوع البحث (التعريف والأهداف) ومحددات التصـيم، ثم ينتقل البحث لعرض الاحتياجـات الإنسانية داخل الفراغات العمرانية والتأثير المتبادل بين الإنسان والفراغات العمرانية. ويشرح البحث طبيعة الأسواق المفتوحة كأحد أهم الفراغات العمرانية

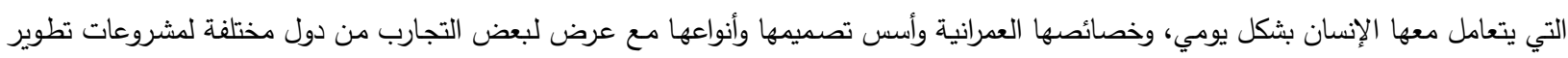
الأسواق، بهدف تحسينها والارتقاء بها ومردود هذا التطوير على السلوك الإنساني.

تتعرض الورقة البحثية لقضية انتشار الأسواق المفتوحة والتي تمثل جزءاً من الفراغات العمرانية والتي تؤثر على سلوك الإنسان، فالواقع يؤكد أن

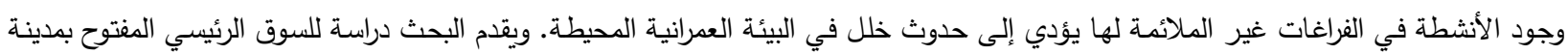
المنيا (سوق الحبشي) وتقديم حلول للارتقاء به من خلال الاستفادة من التجارب السابقة.

وينتهي البحث بمجموعة من النتائج العامة والتوصيات التي يمكن من خلالها استخلاص بعض الحلول الواقعية لمشكلات الأسواق المفتوحة للعمل على الارتقاء بالسلوك الإنساني. الكلمات المفتاحية: الفراغات العمرانية، الأسواق المفتوحة، السلوك الإنساني، الفراغات التجارية، الأسواق العشوائية.

يتمثل الهدف الرئيسي من البحث في محاولة الارتقاء بالسلوك المقدمة:

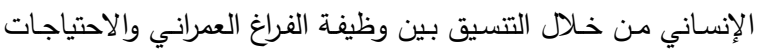

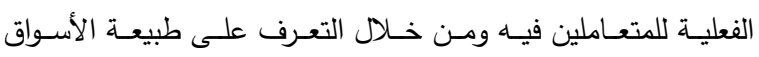
المفتوحة كنموذج للفراغ العمراني المفتوح، ومردودها على الإنسان ومن

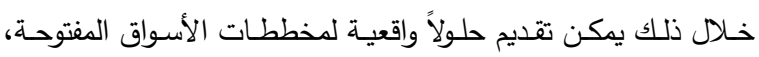
بهدف الارتقـاء وتطـوير وتحسين السـوك الإنسـاني داخـل الفراغـات

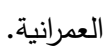

\section{منهحية البحث:}

في الدراسـة النظريـة يعتمـــ البحـث على المـنهج الوصـفي

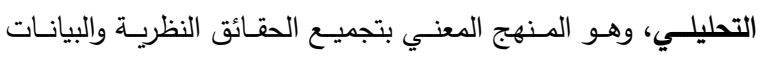

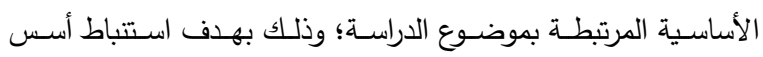
تصميم الغراغات العمرانية، وعلاقتها بالأسواق المفتوحة.

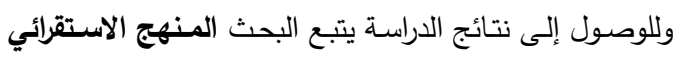
الاستنباطي، من خلال عرض وتحليل بعض النماذج العالمية والمحلية

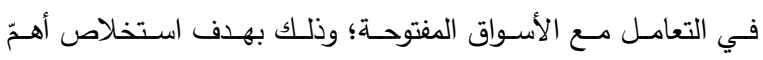
الدروس المستفادة من أساليب وطرق التعامل مع الأسواق المفتوحة. المشكلة:

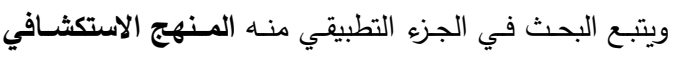

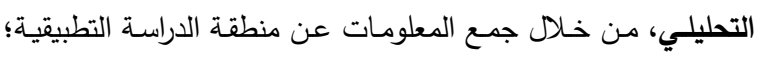
وذلك عن طريق الملاحظة المباشرة والمقابلات وقوائم الاستبيان؛ ثم تحليل المعلومات المتاحة، لاستخلاص النتائج والمؤشرات التي تئدي وني إلى استخلاص النتائج واقتراح التوصيات المناسبة والتي تهدف إلى لى إن غالبية مشروعات التخطيط والتصميم العمراني تركز على

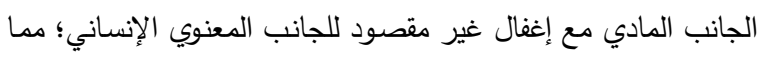

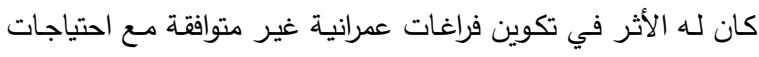

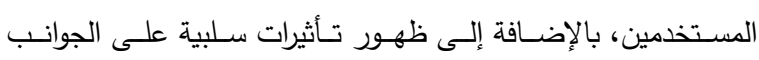
السلوكية والاجتماعية والثقافية؛ مما يدعو المتعاملين مع هذه الفراغات

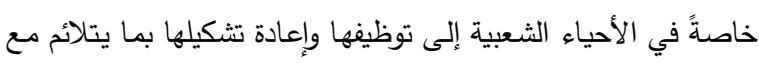
إمكانياتهم واحتياجـاتهم دون تخطيط علمسي أو مشــاركة مـن الجهات المعنية بهذه الفراغات. تهدف عمليات تطوير الفراغـات العمرانيـة إلى توفير الراحـة للسكان، من خلال توفير بعض الخدمات اللازمة في فراغ عمراني له له

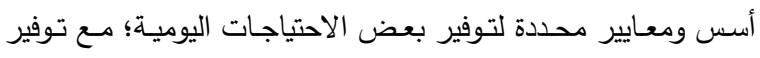
الراحة والأمان للسكان. الارتقاء بالسلوك الإنساني من خلال تطوير منطقة الدراسة المعنية في لتوني 
العمراني هو المجال الذي يهتم بجماليات العمران والبيئة المشيدة وما ينطبع في أذهان المستخدمين من خلال تشكيلاته البصرية6. 1-2-1 أهداف عملية التصميم العمراني: تطرقت الكثير مـن الدراسـات إلى تفسـير أهـداف التصــميم

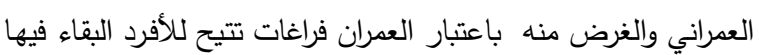

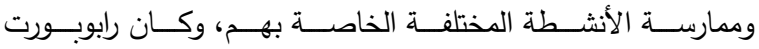
مـ أبرز مـن تنـاولوا أهميـة العمـران حيث أنـه اعتبر (Rapoport) الفراغ العمراني هو ذلك الحيز الذي يذكر الأفراد بالأنشطة التي تدور

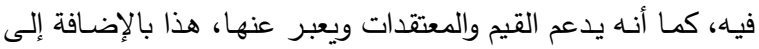
الخصائص والمكونات المادية للحيز والتي تعمل على تمييز الأماكن والملكيات والاستعمالات ومناطق الأنشطة المادية7.7

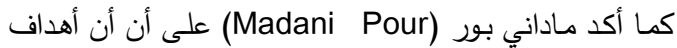
التصــيم العمرانـي هـي التعامـل مـع المحـددات الماديـة والاجتماعيـة للبيئة المبنية وإيجاد التكامل بينهمه هو وقد أضاف لينش (Lynch) هدفاً جديداً للتصميم العمراني وهو تتمية صورة عمرانيـة قويـة وحادة وهذا

يمثل ثغرة ملحوظة في معظم مخططات المدن الحديثة'.

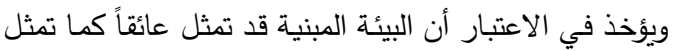

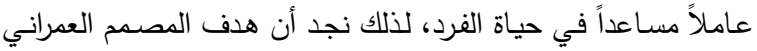
ليس فقط بناء بيئة عمرانيـة فحسب، بل خلق بيئة مسـاندة للإنسـان

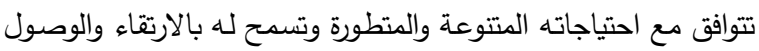

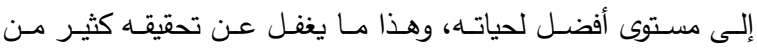

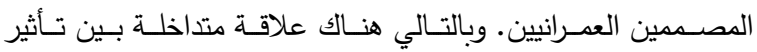

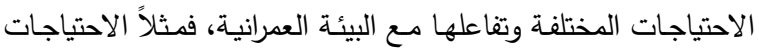
المادية لدرجة إضاءة معينة لها انعكاسات على الراحة النفسية للإنسان

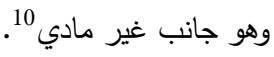
من هنا فالتصميم العمراني يحقق ثلاثة أهداف رئيسية هي: مادي:

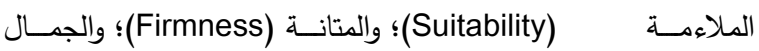

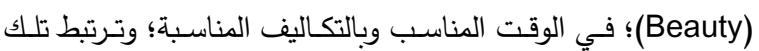
الأهداف بالإنسان وطبيعته وأنشطته وإدراكه للبيئة؛ خاصـة فيما يتعلق

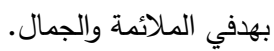

مدـا سـبق يتضـح أن عمليـة التصـميم العمرانـي تهدف إلـى

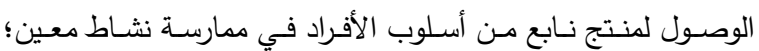
ويتمثل ذلك المنتج في تحقيق إطار مادي واجتماعي وسلوكي لأنشطة

6ـ سيد التوني، "التصميم العمر اني في الدفهوم و الأهمية"، مجلة قسم الهندسة

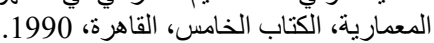

7- Rapoport,A-“The Meaning Of The Built Environment"California,Sage Publica- 1982.

8 -Pour,M,"Design of Urban Spaces"John Wiley,USA, 1996,P(120).

9-Kevin Lynch, "THE IMAGE OF THE CITY", Previous Reference.

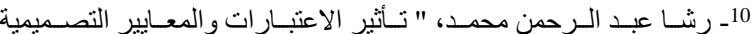

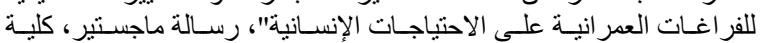

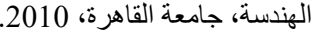

محاولة للمساهمة في حل المشكلات التي تعاني منها وتتسبب فيها الأسواق المفتوحة بها.

1- الفراغات العمرانية:

الفراغ العمراني من أهم عناصر مكونات المدينة، فالمدينة هي

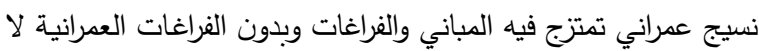

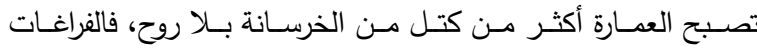

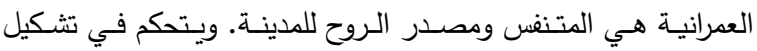

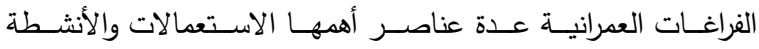
والوظائف التي تؤديها، والتي تنعكس على مقياسها وأبعادها ونسبها

$$
\text { وعلى تصميمها بوجه عام. }
$$$$
\text { 1-1-1 - تعريف الفراغ العمراني: }
$$

اختلفت وجهات النظر في تعريف الفراغ العمراني، فمنها مـا

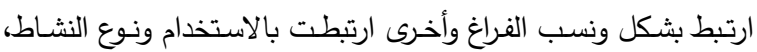
فيعرف (كرير Rob Krier) الفراغ العمراني بأنـه فراغ تتم ممارسـة

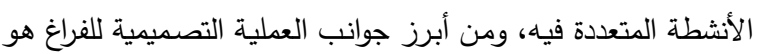

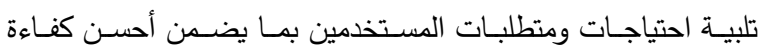
وظيفية للتشكيل 1.

أما (كيفين لينش Kevin Lynch) فقد تعامل معه كقطعة من

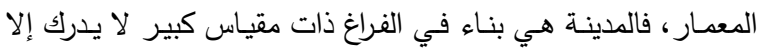

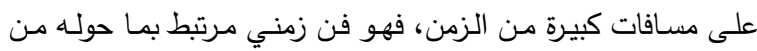

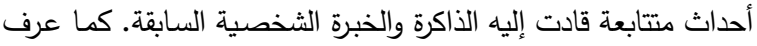

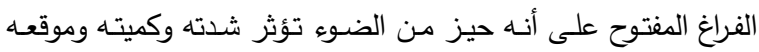
على الإحساس باتسـاع الفراغ وهو بذلك يؤكد البعد الجمالي للفراغ². وقد شـاركه في نفس الإتجاه (زوكر Zucker) الذي وصف الذف العلاقة

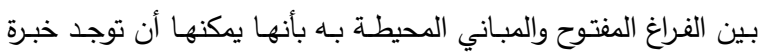
عاطفية صادقة تضاهي الأثر الناتج من أي عمل فني آخر 3.

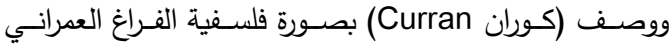
بالمسرح التلقائي الحر حيث اعتبر الفراغ بمثابة خشبة المسرح والسكان

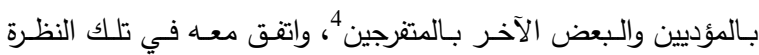

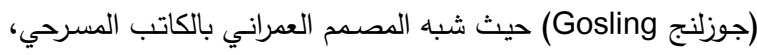
فالتصـيم العمرانـي في نظـره هـو فـن التعامـل المباشـر مـعـ جمهور

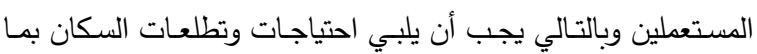
يناسب بيئتهم البصرية من خلال التعبير بالفراغّأ. أما (سيد التوني) فقد وصف الفراغ العمراني بالحيز الجماهيري

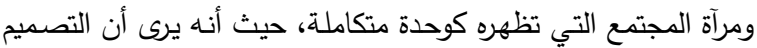

1-Rob Krier "URBAN SPACE" ,Academy Edition, Great Britain,1975.

2-Kevin Lynch," THE IMAGE OF THE CITY",the MIT press, Cambridge, London, 1960.

3 -Zucker,p, "Town and Square: from the Agora the village Green", 1973.

4-curran, R.J.,"Architecture and The Urban Experience". Van Nostrand Reinhold Company, London. 1983. P(24).

5-Gosling, D.a.M.B., "Concepts of Urban Design". 1984: St, Martin;s press, New York. 
الآخرين6، لذلك فقد اهتم حسن فتحي بالتمييز بين متطلبات الأفراد من

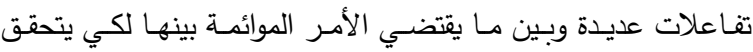

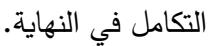

\section{1-5-1 التأثير المتبادل بين البيئة العمرانية والسلوك الإنساني:}

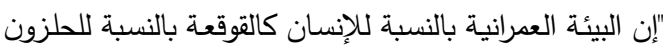
فهي تشكل جسمه في داخلها حسب شكلها، وهي هذا الثكل الذي

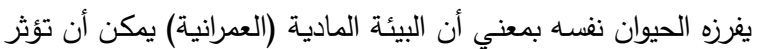

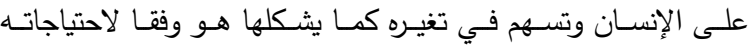

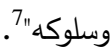

من هنا يتضـح أهمية الاعتبارات الوظيفية للأنشطة والأنساق

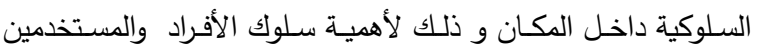
داخل الفراغ. ويتضـمن ذلك دراسـة وتحليل الفراغات العمرانية والبيئة

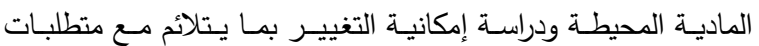
المستخدمين وذلك في ظل تعدد الأنساق السلوكية للمستعملين حيث إن الوعي الكامل بطبيعة النشاط يأتي من تحديد المسطح الحاوي لهذا لهائ النشاط وظيفياً.

كذلك يذكر (Lynch, 1960) أن المصممين يشكلون البيئة

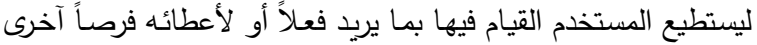

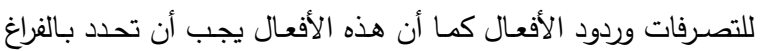
والتجهيزات، من هنـا يمكن القول أن الوظيفة ينبغي أن تكون ملائمـة

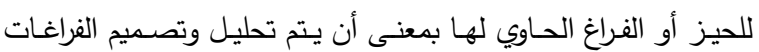

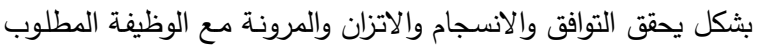

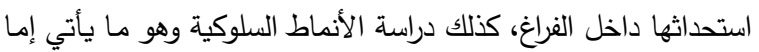
بالملاحظة المباشرة أو غير المباشرة أو الاستبيان 8.

2- الأسواق المفتوحة:

هناك العديد من الأنشطة التي تدور داخل الفراغات العمرانية منها الأسواق المفتوحة، والتي تعتبر ذات أهمية كبيرة في حياة الإنسان

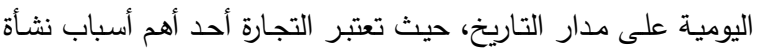

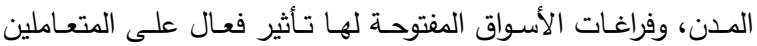
داخلها وبالتالي التأثير على السلوك الإنساني. 1-2 - أهمية السوق قديماً:

يعتبر السـوق أحد العناصـر الأساسية التي شكلت تخطيط المدينة العربية الإسلامية منذ نشأتها، وذلك لما للتجارة من أهمية كبيرة

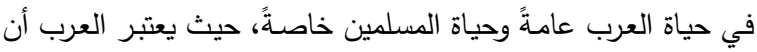
التجارة تمثل تسعة أعشار الرزق. ومـن جانب السلوك الإنسـاني فقد

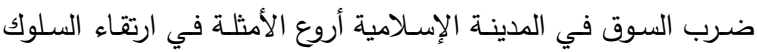
بين المشترين والتجار ، فلم يقتصر السوق فقط على تبادل المنافع

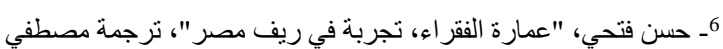

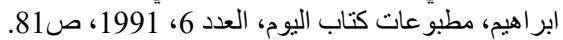
7ـ حسن فتحي "عمارة الفقر اءع", الهيئة المصرية للكتاب، 2001.

8. Kevin Lynch, "THE IMAGE OF THE CITY", Previous Reference.
ووظائف إنسانية. وبالتالي؛ فإن الهدف من عملية التصميم العمراني للفراغات يتضمن تحقيق متطلبات وظيفية لأنشطة الأفراد؛ كما يمتد إلى توجيه السلوك بما يتلاءم مع تلك الوظائف. لذلك؛ فإن الاعتبارات الاجتماعية والثقافية والسلوكية هي الموجها الفعلي للعملية التصميمية

|-1-3-1 محددات تثكيل الفراغ العمراني:

إن عملية التشكيل العمراني نتاج لتفاعل العديد من العوامل

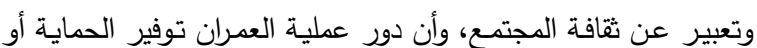
تحقيق الاحتياجات النفعية للإنسان².

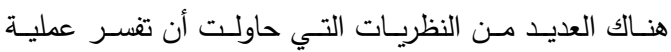
التثكيل العمراني، ولكن بعض هذه النظريـات ترجع عملية التثكيل

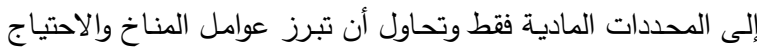

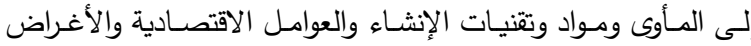

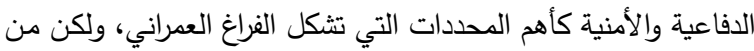

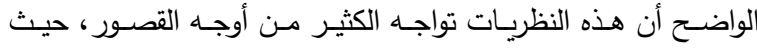

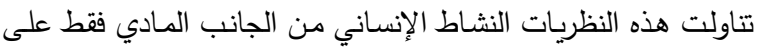

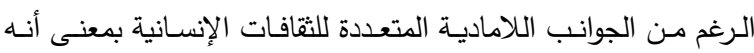

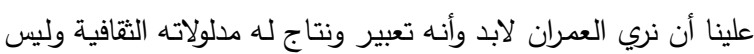
فقط العناصر المادية.

1-4- الاحتياجات الإنسانية داخل الفراغات العمرانية:

يقصـد بالاحتيـاج هـو حالـة مـن عدم الثـعور بالرضــا نتيجـة

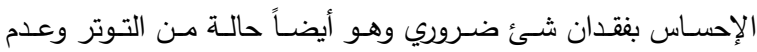
الاتزان في البيئة والذي يدفع الإنسان بإطلاق السلوك بهدف التخفيف من التوتر أو تحقيق الاتزان3.

وقد اختلفت أراء المفكرين والمهتمين في إيجاد تعرنف للاحتياج ومنها: عـرف المفكـر الفرنسـي (Lamartine) الحاجـة علـى أنهـا المحرك الأقوى أثراً في الحياة، وأن التقدم يتعين درجته على قدرته على الحركة لسد الحاجة، وأن الإنسان يحتل المقام الأول بين الكائنات

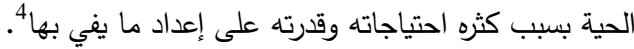
كمـا رأى (Karl Marks) أن الحاجـات التي يسـى إعى الفرد

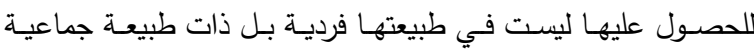
اجتماعية ناتجة من تعاون وتعامل بين مجموعة من البشر 5. اعتبر (حسن فتحي) الاحتياج هو تعبير عن الفرديـة واستند

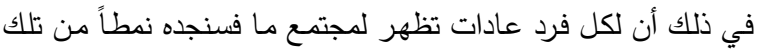

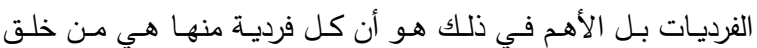

1.- Moore,G.T-"Environment Behavior Studies" .New York.Mac Graw-Hill 1979.

2 -Rapoport,A-“"The Meaning Of The Built Environment"California,Sage Publications- 1982.

3 -Forti, "Research \& Human Needs", Augusts and Bisogono, Paoloed, 1981,P (11).

4ـ عبد الفتاح إبر اهبم، "الاجتماع"، دار الطليعة، بيروت، 176، 1971، ص 130.

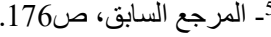

$-4-$ 


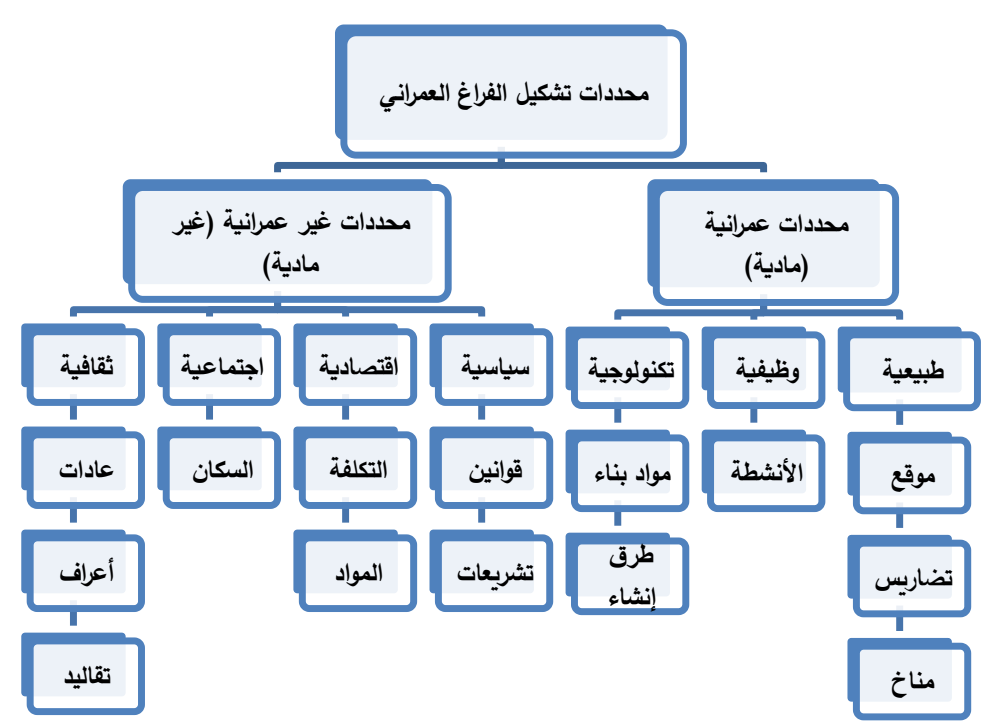

شكل (1) محددات تثكيل الفراغ العمراني.

(المصدر: رشا عبد الرحمن، " تأثير الاعتبار ات والمعايير التصميمية للفر اغات العمر انية على الاحتياجات الإنسانية"، رسالة ماجستير ، كلية الهنسة، جامعة القاهرة،

$(2010$

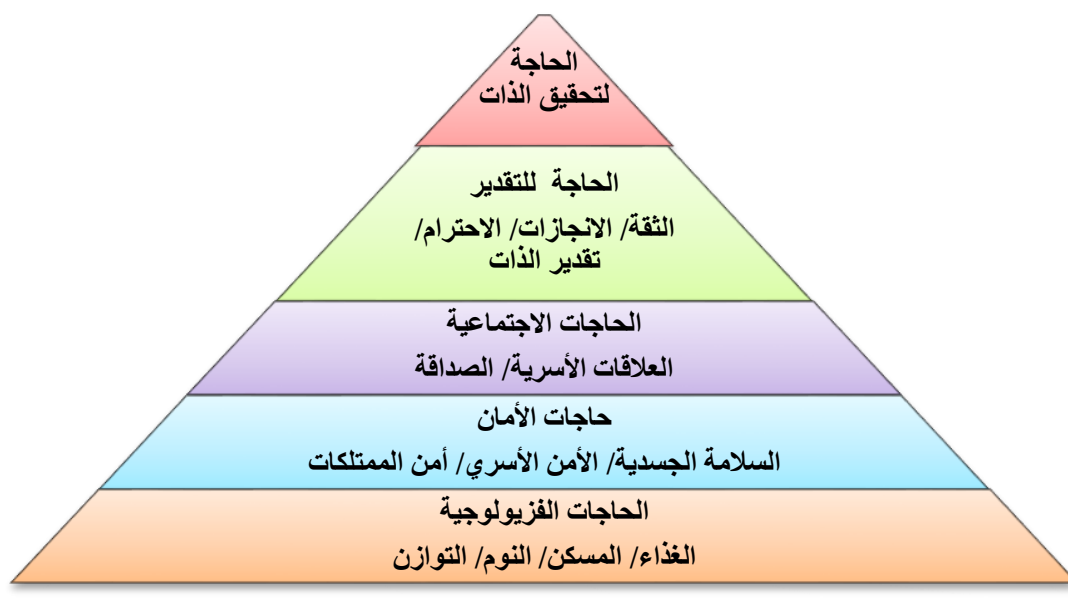

شكل (2) هرم ماسلو للاحتياجات الإنسانية.

(المصدر: رشا عبد الرحمن، " تأثير الاعتبارات والمعايير التصميمية للفراغات العمرانية على الاحتياجات الإنسانية"،مرجع سابق) الانسانه)

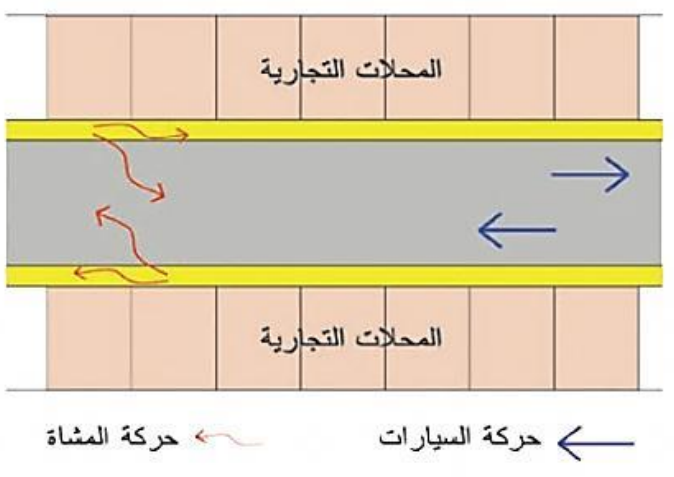

شكل (3) السوق عبارة عن شارع تجاري للسيارات وإلمشاة.
والتعارف بين المسلمين ولكن كان أيضاً لترسيخ تعاليم الدين الإسلامي لتحسين سلوك الإنسان، ومن أمثلة ذلك عندما مرَ رسول الله (صلَ الله

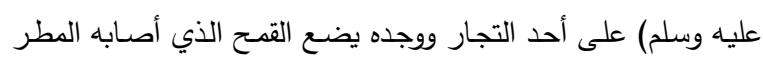
من أسفل في صُبرة القهح، فعاب عليه ذلك وقال لـه (من غشنا فليس

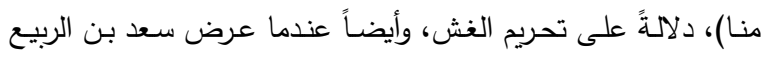

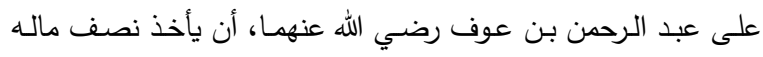
رفض ذلك وقال له (بل دُلني على السوق) مما يدل على أهمية التجارة في كسب الرزق ونشر تعاليم الدين الإسلامي.

أ- الأسواق الخطية: وهي الأسـواق التي تقـع على محساور الحركة الرئيسية، وتأخذ شكل

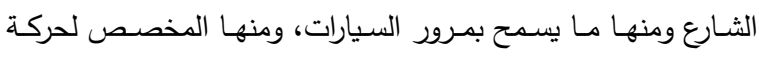
المشاة؛ وهو الأفضل من حيث توفير الأمان للمترددين على السوق. 


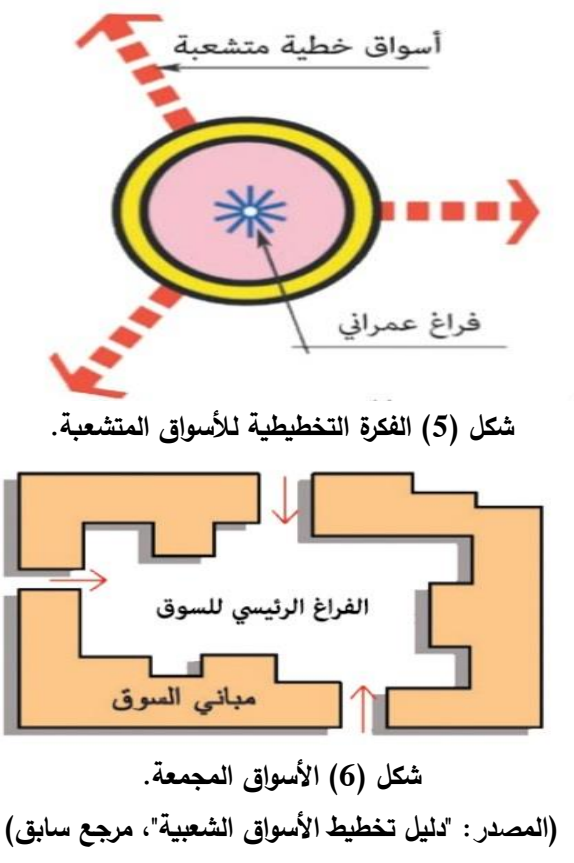

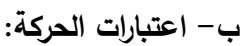

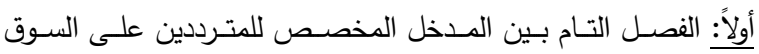
(الجمهور ) وبين المدخل المخصص لسيارات النقل الخاصة بالبضائع. ثانياً: الدخول إلى السوق من خـلال طريق خدمة وليس من الطريق لئيق

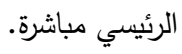

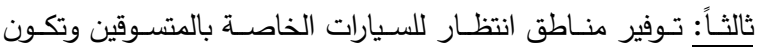

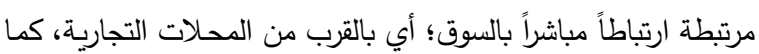
يتم توفير أماكن انتظار لسيارات النقل الخاصة بنقل البضائع وتكون

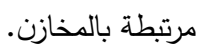
رابعـاً: الفصـل بين المسـارات المخصصـة لحركـة المشـاة، والمسـارات المخصصة لحركة السيارات داخل السوق؛ مع ملاحظة ارتباط مسارات المشاة بأماكن انتظار السيارات للمتسوقين.

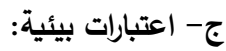
يجب مراعاة الظروف المناخية للمنطقة عند تخطيط السوق واستخدام مواد محلية ملائمة للبيئة في عملية الإنشاء، ويضضل استخدام مسارات المشاة المظللة لتسهيل عملية التسوق على الجمهور.

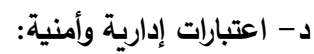
يجب الالتزام باشتراطات الدفاع المدني لتحقيق السلامة والوقاية من الدارية

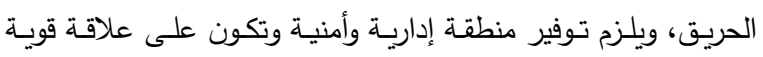
بدذل السوق والمنطقة التجارية.

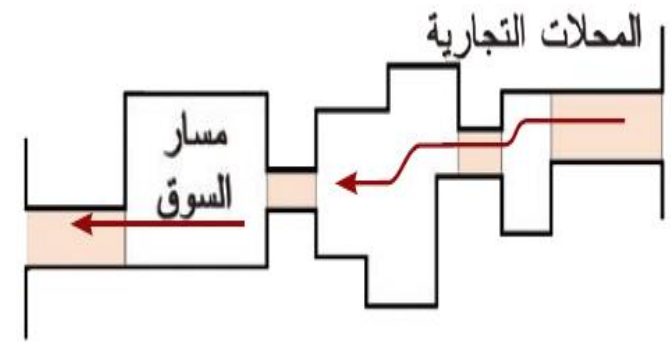

شكل (4) السوق عبارة عن شارع تجاري للمشاة فقط. (المصدر: "لليل تخطيط الأسواق الثعبية"، وزارة الثشئون البلاية والقروية،

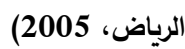

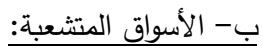

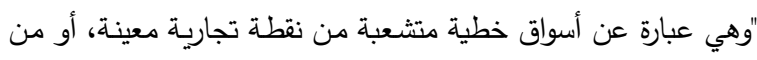
فراغ عمراني يتميز بنشاط معين، مثل فراغ المسجد الذي تتشعب منده

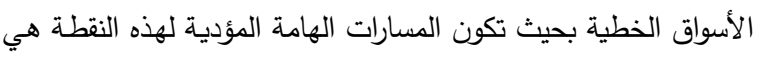

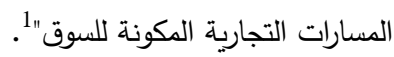
ج- الأسواق المجمعة: هي عبارة عن تجمع للسوق التجاري حول فراغ عمراني تتم فيه عملية البيع والثراء بداخل السوق، مما يوفر حركة آهنة لحركة الششاة بداخل

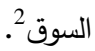

3-2-2 الاعتبارات الأساسية لتخطيط السوق3:

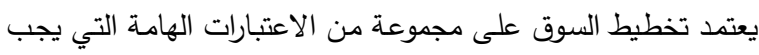
اتباعها عند إعداد مخطط السوق؛ وتتلخص هذه الاعتبارات فيمـا

أ- اعتبارات توزيع الاستعمالات:

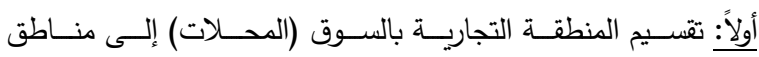
متخصصة حسب نوع السلع لتحقيق سهولة التعامل. ثانياً: توفير منطقة خدمات السوق (دورات مياه - مسجد - كافتيريات - منـاطق جلوس...) وارتباطها بالمنطقة التجاريـة لخدمـة الجمهور

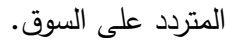

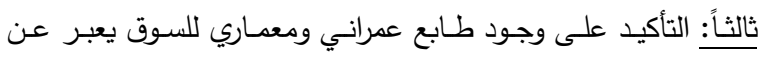
انعكاس البيئة المحلية والنابعة من ثقافة وطبيعة المنطقة والمواطنين.
1- "دليل تخطيط الأسواق الثعبية"، وزارة الشئون البلدية والقروية، الرياض، 2005 2ـ زينب فيصل، "و واقع الأسو اق التقليديـة في الدينـة المعاصرة"، مرجع سابق. 

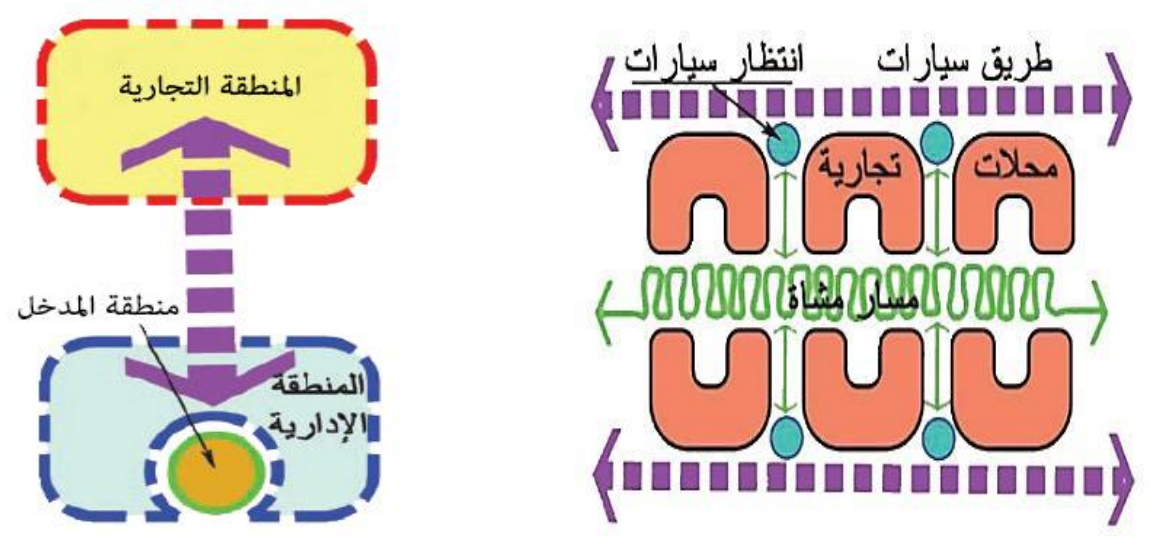

شكل (8) ارتباط المنطقة الإدارية بالمدخل والمنطقة التجارية بالسوق.

شكل (7) الفصل بين حركة المشاة وحركة السيارات.

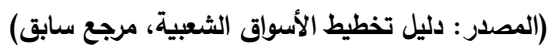

النظـر إلى الأسـواق العشـوائية مـن منظـور عدم الالتزام

بالإجراءات القانونية وأغفل باقي العناصر الأخرى.

الأسـواق التـي تقـدم الســلع أو الخـدمات بشـوارع المدينـة،

والسـاحات، والحـدائق، وحـول محساور النقل، وغيرهـا مـن

الأماكن العامـة الحضرية، من خـلال هيكل دائم لأعمالهم

$$
\text { التجارية. }
$$

وممـا سبق ومـن خـلال عرض لمجموعـة التعربفـات السـابقة للأسـواق العشوائية تم الوصول إلى تعربف ملخص للسوق العشوائي:

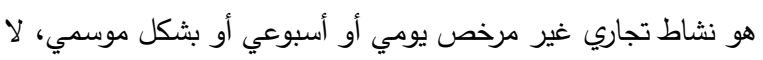

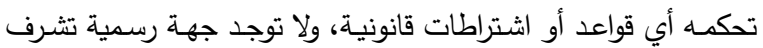
عليه، وينشأ في مناطق مختلفة غير مخططة لهذا النشاط، مستغلاً

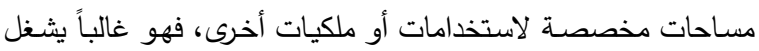

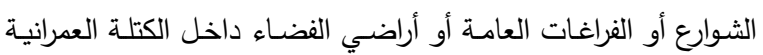

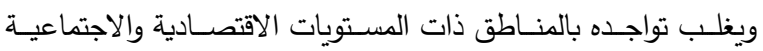
الأقل، ولا يوجد لوحداته شكل ثابت. 2-5-2 تصنيفات الأسواق العشوائية: صنفت الدراسة التي أعدها جهاز صندوق تطوير العشوائيات

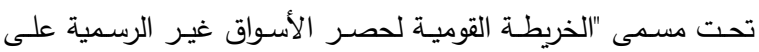
مستوى جمهورية مصر العربية"3، تبعاً للشكل التالي.

3- تجارب تظوير الأسواق في دول العالم: تم وضـع عدة معـايير في اختيـار هذه التجـارب وذلكك على النحو التالي:- أن يكون السوق من الأسواق القديمة. - يتسم السوق بأهمية اقتصادية كبيرة في المدينة.

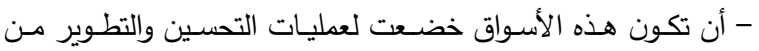
خلال مشروعات إعادة تخطيط.

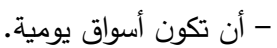

3ـ صندوق تطوير المناطق العشو ائية، مرجع سابق.
2-2-2 مفهوم الأسواق العشوائية: يعرف جهاز صـندوق تطوير العشوائيات الأسـواق العشوائية

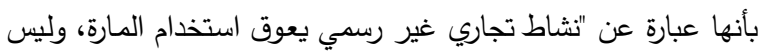

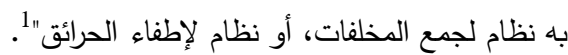

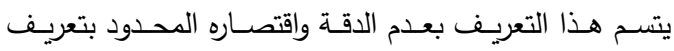

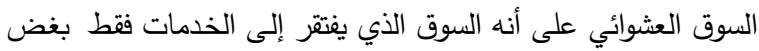

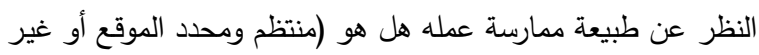

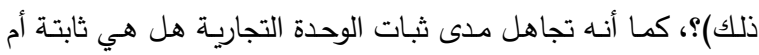

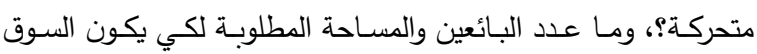
عشوائي؟، والأهم هو موقفه من الجانب التخطيطي للمدينة أو للمنطقة السكنية وعلاقته بالمحيط العمراني.

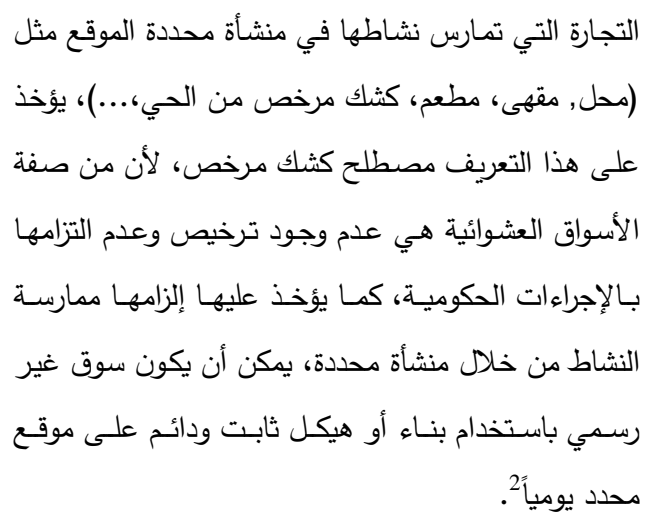$$
\text { مفاهيم أخرى: }
$$
مجموعة الأنشطة الاقتصـادية التي تمـارس نشـاطها خارج الإطلار القانوني ولا تتطلب تأهيلات وقدرات عالية مقارنة بنظيرتهـا في القطـاع الرسـي، ركز هـذا التعريـف على 1-ـ صندوق تطوير المناطق العشو ائية، http://www.isdf.gov.eg.

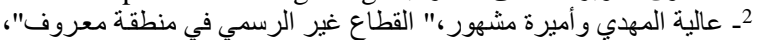
المركز القومي للبحوث و الدراسات الاجتماعية و الجنائية، القاهرة, 1994. 
ظل السوق صـامداً أمام تغييرات عديدة كالحروب والكوارث

مـن خـلال التطـوير وتجديـد البنيـة الأساسـية للسـوق، وأصسبح يضــخ

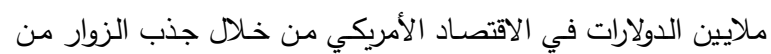

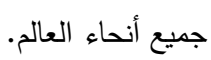

ب-سـوق (Galleria Vittorio Emanuelle) - مسيلان إيطاليا:

يعتبر جاليري فيتوريو إيمانويل من أكثر أسواق ميلان تميزاً فهو يعكس عدة قيم: - مديم

القيمـة التاربخيـة: فقد بُنـي السـوق منـذ أكثر مـن 130 عـام،

ويمثل قيمـة تاريخيـة على المستوى المعمـاري فهو يعبر عن التغيرات المعمارية والاجتماعية التي صحبت الثورة الصناعية بميلان، من خـلال استخدام الحديد والزجاج في العقود التي تغطي الممرات، كما يمثل قيمة تاريخيـة ذات صبغة سياسية تكمن في تعبير المبنى عن اتحاد إيطاليا بربط أماكن تاريخية ببعضـها بمحاور الجاليري الرئيسية، ومـن الجدير بالذكر أن سكان ميلان عارضـوا في البدايـة المشـروع بشـدة لإحساسـهم وقتها بأنسه سيدمر الجزء التـاريخي ( منطقـة الكاتدرائيسة ودار أوبرا سكالا ) إلا أنهم سرعان ما تقبلوا المشروع بممراته الرائعة (The living room of وأطلقوا عليه غرفة معيشة ميلان Milan )

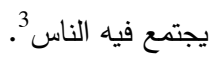

القيمـة الاقتصـادية: يمثل السوق قيمـة اقتصـادية كبيرة لمدينـة ميلان، لاحتوائه على عدد كبير من أعرق وأكبر المحسلات والمطاعم والكافتريات الجالبة للسياحة الداخلية والخارجية، مثل (Savini Restaurant / Biffi Cafe) بالذكر أن ميلان تعتبر المركز الاقتصسادي الأكثر أهمية في إيطاليا حيث أعطاها موقعها الجغرافي مميزات لتصبح مركزاً للتسوق، كما أن ميلان بها معظم أسواق الجملة الإيطالية. القيمـة المعماربـة: يمثل السوق قيمـة معماريـة وجمالية عظمى لمـا فيه من جمل معماريـة ذات الطراز الكلاسيكي والباروكي بكلاً من الواجهات الداخلية والخارجية.

يوجد السوق بمدينة ميلان بإيطاليا محوره الثمالي الجنوبي

بطول 195م تقريباً، يصل بين الساحة الثمالية (Piazza del la) scala

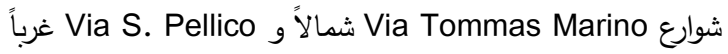
و Via U. Foscolo شرقاً.

${ }^{3}$-http://aviewoncities.com
- أن تكون أسواق غير متخصصة (سوق عام).

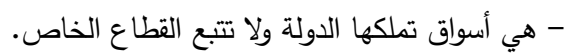
- وجود تشـابه إلى حد كبير بينها وبين الأسواق في المدينة العربية عامة والمصرية خاصة. تم اختيار أربعة أسواق مختلفة من أربعة دول مختلفة لأسواق تجاربـة خضعت لعمليات النطوير لتحقيق الاستدامة وهي:أ- سوق (French Market) - نيو أورلينز - الولايات المتحدة. ب- سوق (Galleria Vittorio Emanuelle) - ميلان - إيطاليا. ج- سوق (Kapali Çarsi Grand Bazzar) - إسطنبول - تركيا.

$$
\text { د- سوق (محايل عسير) - محايل - السعودية. }
$$

أ- سوق (French Market) - نيو أورلينز - الولايات المتحدة: يعتبر السوق الفرنسي من أكثر أسواق ولاية لوزيانـا بالولايات المتحدة الورلينز تميزاً فهو يعكس عدة قيم 1:القيمـة التاربخيـة: فقد بُني السـوق منـذ أكثر مـن 200 عـام،

وتأثر بالعديد من الثقافات كالإسبانية والفرنسية والإيطالية. القيمة الاقتصادية: يلعب السوق الفرنسي دوراً هاماً ورائداً في بالي الاقتصـاد المحلي وتوفير عائدات متزايـدة باستمرار لحكومـة المدينة. القيمـة التجاربـة: تُباع بالسوق العديد من أنواع السلـع كـاللحوم والأسماك والخضـروات والفاكهـة... وغيرهـا، بالإضـافة لوجـود العديـــــن المطـاعم المميـزة بالسـوق والتـي تثـتهر بتقديمها لوجباتها مع الموسيقى، وهذا المزج أضفى طابعاً مميزاً للسوق

فيما يعرف بـ "Gumbo Style".

يقع السوق بمدينة نيو أورلينز بولاية لوزيانا بالولايات المتحدة

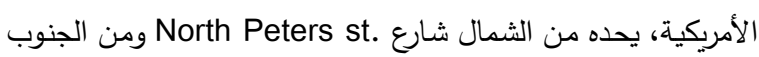
French ومن الثرق Barracks st. ومن الغرب Ursuline st. market pl. والتجارية عدا الجهة الجنوبية حيث يوجد خط سكة حديدية مطلة على نهر المسيسيبي. لأكثر من 200 عام، كان السوق الفرنسي رمزاً دائماً للفخر والتقدم لثعب نيو أورليانز ، وعلى الرغم من وجود السوق في نفس الموقع منذ

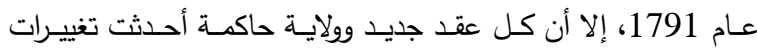

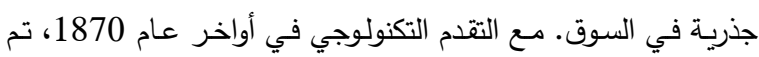
بنـاء هيكل يعرف بإسـم سـوق البـازار فكانـت المههـة الأساسـية التـي تواجه الحكومات هي إعادة تأهيل السوق وتحديثه، وفي عام 1971

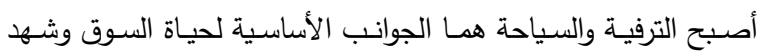
السوق تطوراً كبيراً مثل إضافة الأعمدة والتماثيل التاريخية2.

${ }^{1}$-www.frenchmarket.org/history.

1- John Magill, "French Market Celebrates 200"th Anniversary", PIP article, the magazine of the preservation center, 1991. 


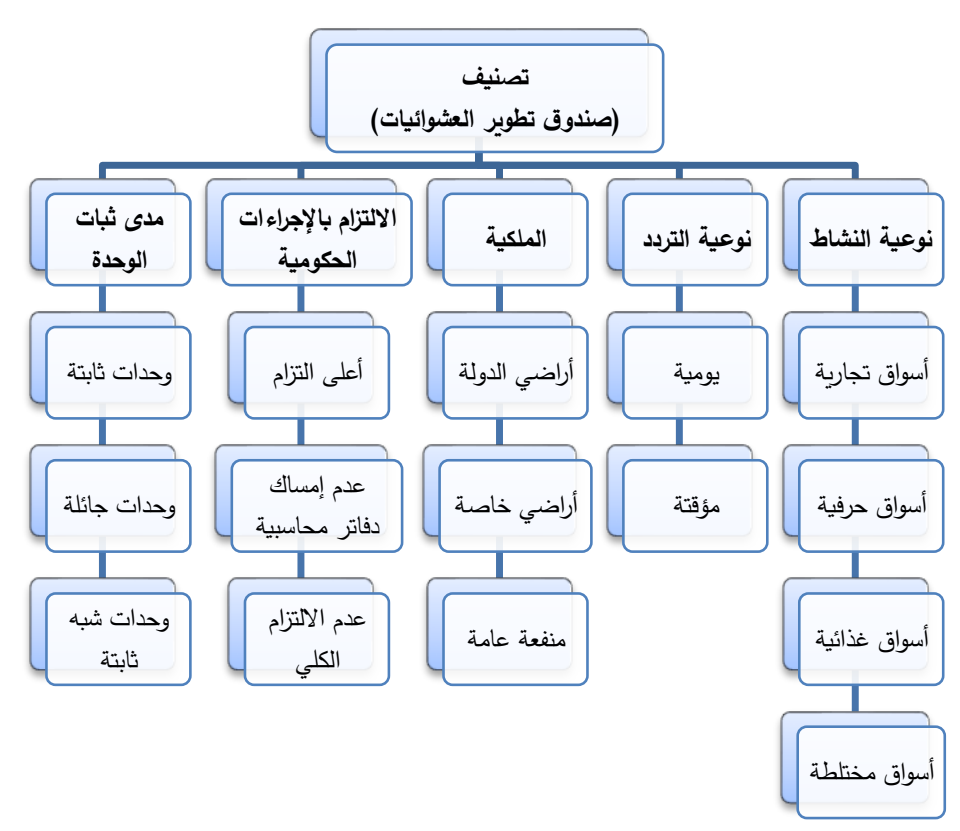

شكل (9) تصنيف الأسواق العشوائية

(المصدر: صندوق تطوير المناطق العشوائية)

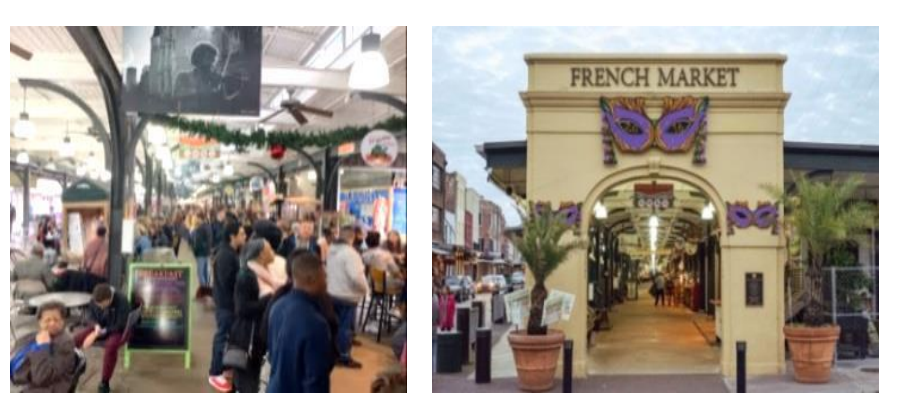

شكل (11) سوق French Market
French Market PI.

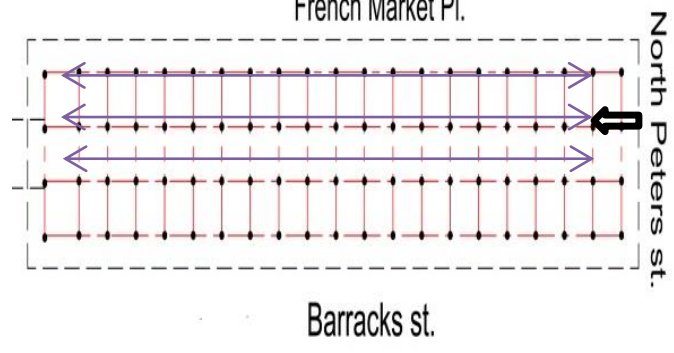

شكل (10) المسقط الأفقي لسوق French Market

(المصدر: (http://billespartners.com)

القيمة التاربخية: فقد بُني السوق منذ أكثر من 550 عامـاً بالإضـافة لموقعه التاريخي أيضـاً، ويعد هذا السوق انعكاسـاً

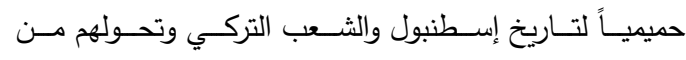

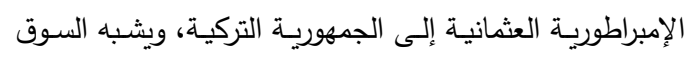
لحد كبير المتحف.

القيمة الاقتصادية: يمثل السوق قيمة اقتصادية كبيرة جداً فهو

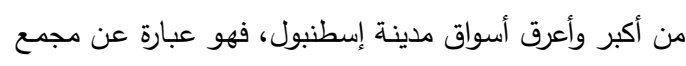

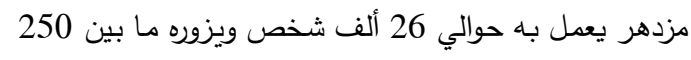

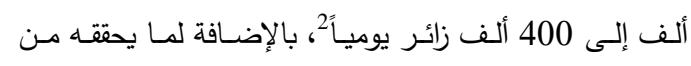

\footnotetext{
2. Celik, "Story of the Grand Bazaar", Istanbul, 1980.
}

وُضع حجر الأساس للسوق بواسطة الملك إيمانويل الثاني في مـارس عـام 1865، بحضـور العديد من السلطات وفي عـام 1869 قامت الثركة المنفذة بالإفلاس، الأمر الذي أجبر مجلس المدينة على ملى الفيل تولي بقية العمل، ولحق بالسوق أضرار جثيمة بسبب التفجيرات التي

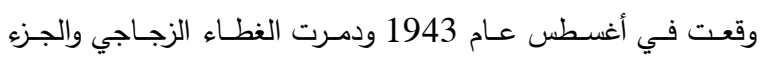
العلوي من الغطاء المعدني، وتم الانتهاء من ترميم السوق عام 1955

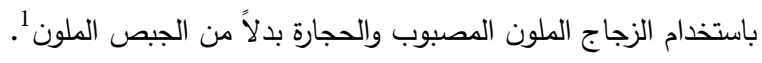
ج- سوق (Kapali Çarsi Grand Bazzar) - إسطنبول تركيا: يعكس سوق Kapali Çarsi عدة قيم كانت سبباً جوهرياً في اختياره:

1- Progetto, "La Galleria Vittorio Emanuele di Milano", Ornella Selvafolta, DS Comunicazione, 2016 


$$
\text { اتسع السوق التركي يوماً بعد يوم وتمت فيه الترميمات }
$$

والإصداحات بعد الزلازل والحرائق التي حدثت من زمن إلى زمن حتى ئى

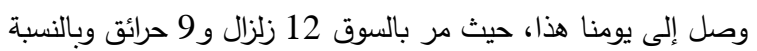

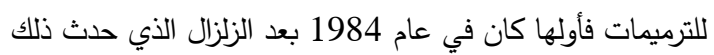
العام، والثاني في عام 1994 بعد حدوث حريق كبير.

$$
\text { والبضائعدات اقتصـادية كبيـرة كمـا أن وجـود الكثيـر مـن التحففية يضفي قيمة اقتصادية كبيرة للسوق أيضاً. }
$$$$
\text { يوجد السوق بمدينة إسطنبول بحي الفاتح ويمتد من جامع بيازيد غرباً }
$$
إلى جامع نورعثمانياً شرقاً وله إله 18 مدخل.

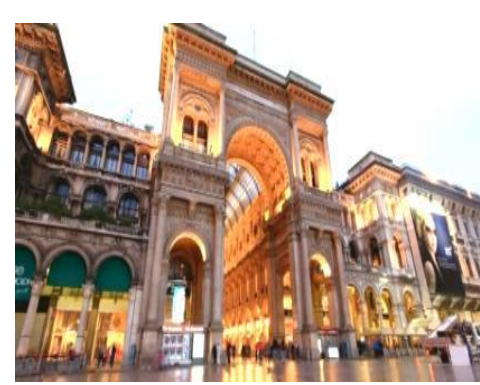

شكل (13) سوق Galleria Vittorio Emanuelle

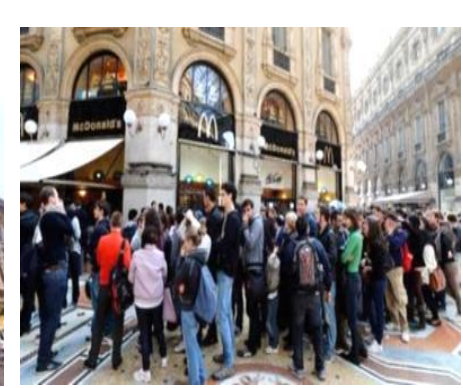

شكل (12) المسقط الأفقي لسوق Galleria Vittorio Emanuelle

(http://greatbuildings.com : المصدر))

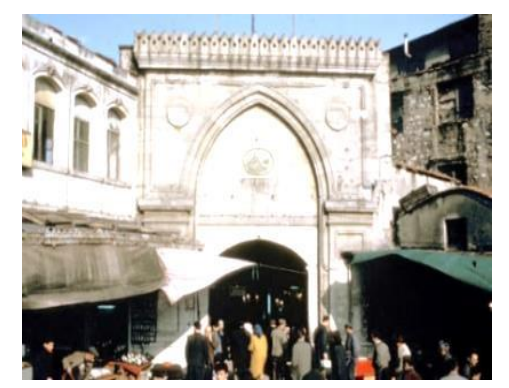

شكل (15) سوق Kapali Çarsi Grand Bazzar

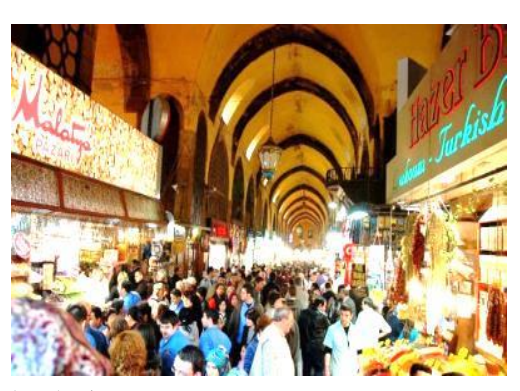

شكل (14) المسقط الأفقي لسوق Kapali Çarsi Grand Bazzar

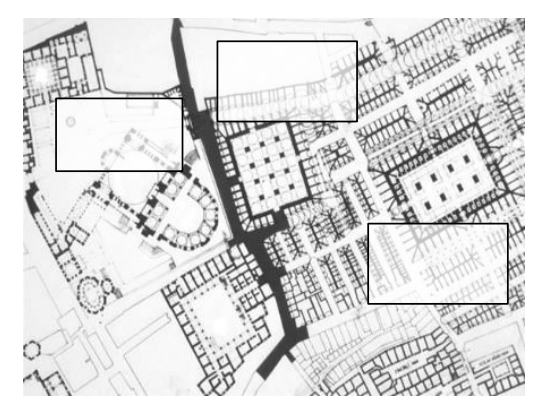

(المصدر: (http://greatbuildings.com)

الحجارة، وقد قامت البلدية بإنثاء مظلات لعدد من المحال والبسطات

$$
\text { التي تحوي أنثطة مختلفة } 1 .
$$

اعتمدت فكرة تطوير السوق على إعادة تصميم مبنى السوق،

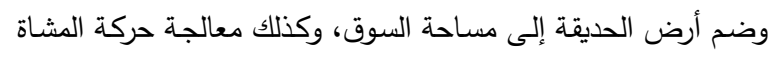

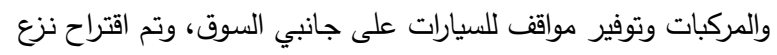
ملكية السوقين اللذين يقعان على جـانبي السوق، وإعادة تصـيمهما ضمن منظومة تطوير السوق، كما شملت الفكرة تخصيص مساحات

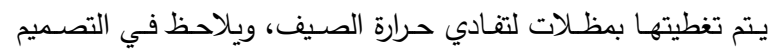
المقترح الحفاظ على الطابع التراثي المحلي لمنطقة عسير، بما يعكس لئل

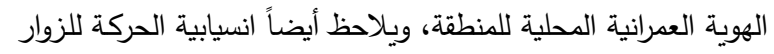
ومرونـة خط سـير السـيارات ونسـبة المسطحات الخضـراء المحيطـة ونسة

بالسوق.

1"_" برنامج تطوير و إعادة تأهيل الأسواق الثعبية في المملكة العربية

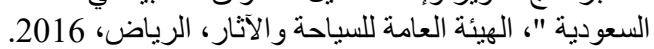



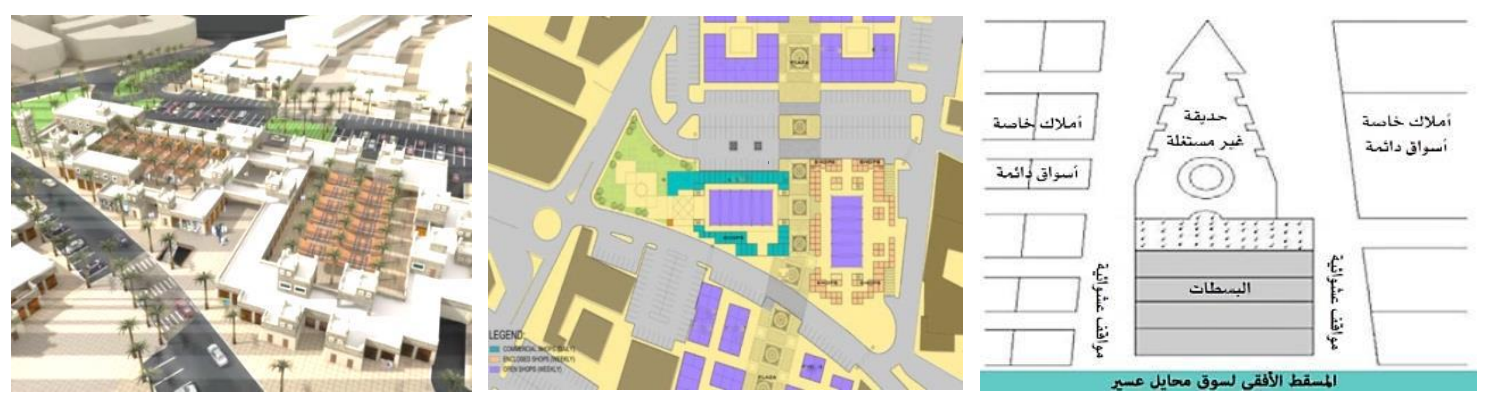

شكل (16) سوق محايل عسير قبل وبعد التطوير.

(المصدر: " برنامج تطوير وإعادة تأهيل الأسواق الثعبية في المملكة العربية السعودية "، مرجع سابق)

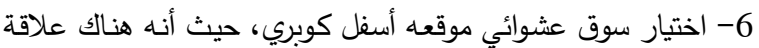

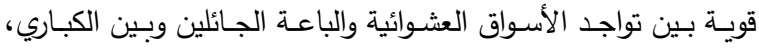

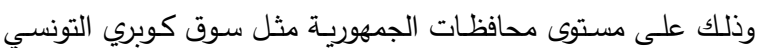
وسوق كوبري السيدة عائشة بالقاهرة.

4- دراسة الحالة: دراسة ميدانية لسوق الحبثي بمدينة المنيا:

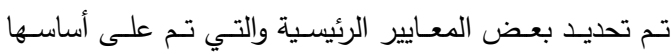

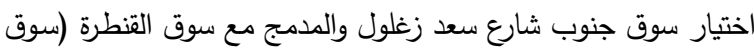
الحبشي) للدراسة التطبيقية وهي كالتالي:

1-4 - الدراسة التخطيطية: يعتبر سوق منطقة الحبشـي بوسط مدينـة المنيا، مـن أشـهر

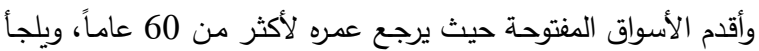
إليه أصحاب الطبقة الفقيرة والمتوسطة من سكان مدينة المنيا والقرى المجاورة، وأطلق عليه البعض "سوق الغلابة". يقع سوق الحبثي بداية

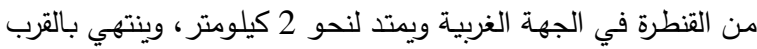
من نهايـة كوبري محمد بدوي من الجهة الشرقية المطلة على شـارع كورنيش النيل.

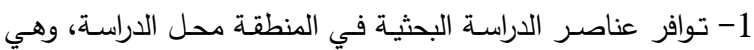
السوق العشوائي والثراغات العمرانية أسفل كوبري محمد بدوي. 2- كبر حجم سوق الحبشي وتثعب وحداته أسفل كوبري محمد بدوي وبالغراغات العمرانية المحيطة. 3- وجود نشـاط دائم أو دوري في منطقة السوق، حيث تحسول مـن سوق إسبوعي إلى سوق يومي. 4- تتوع تواجد الأنشطة بالمنطقة مـا بين رسمي وعشوائي وغذائي

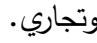
5- اعتمـاد سـكان المنطقــة بثـكل كبيـر على النثـاط الحـادث في السوق، أو أن يكون مؤثراً في حياتهم المعيشية.

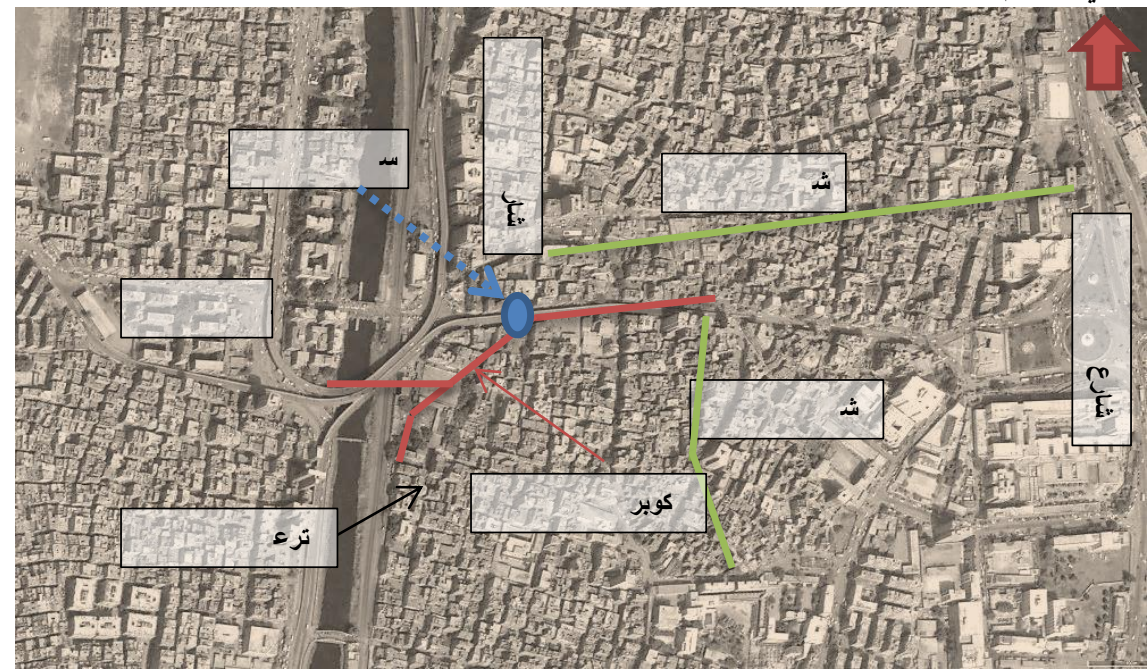

شكل (17) الموقع العام لكوبري محمد بدوي وسوق الحبثي محل الدراسة.

(www.Google map.com:المصدر)

يسـى بمحساور انتشـار السـوق، مثل شـارع الحسيني القبلي وكنيسـة

العذراء جنوباً، وشارع محمود عبد الرازق ومسجد الحبشي شمالا.

يعتمد سوق الحبثي على النشاط الغذائي، حيث يحتوي على

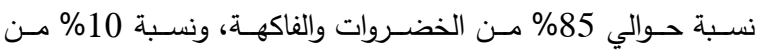
منتجـات الألبان و5\% مـن مـواد العطارة، وبـالرغم مـن عدم تصـيم

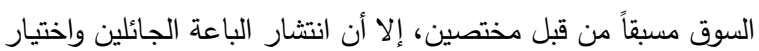

لــوحظ مـن خــال الزيــارات الميدانيـة التشــب والانتثــار

الواضحين لمنطقة السوق، حيث يزداد عدد الباعة بشكل كبير في يوم

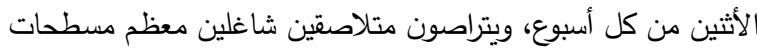

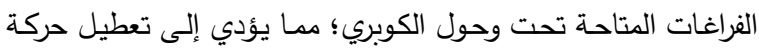

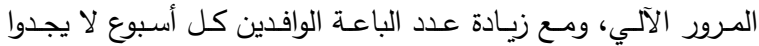

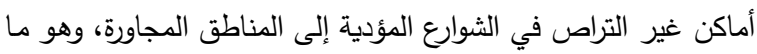


من اتخذ مكاناً دائماً في السوق، ومن خـلال رصد الكثافات البشرية لوحظ وجود ازدحام في ثلاث مناطق رئيسية أسفل كوبري محمد بدوي

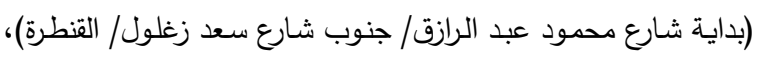
خاصةً يومي الأثنين والثلاثاء.
الباعـة الدائمين لأمـاكن بـيعهم حسب نثـاط كـلٍ منهم، جـاء بشكل

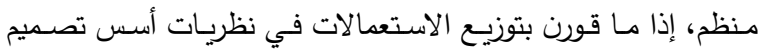
الأسواق التجارية المفتوحة.

تتعدد أشكال تواجد البائعين في السوق، فمنهر من يأتي بشكل

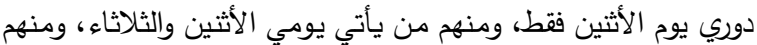

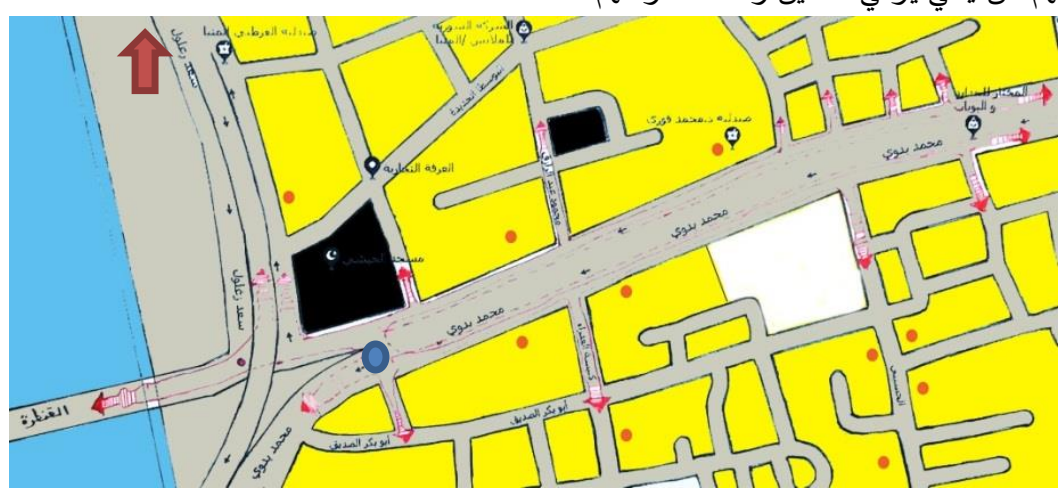

$$
\text { شكل (18) محاور الانتشار لامتداد السوق في أوقات الازدحام. }
$$

لسوق الحبثـي، والفوائد التي تعود عليهم وعلى المجتمـع من وجـود

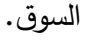

-2-4 - الدراسة الاستطلاعية:

تحليل الأسئلة ذات النهايات المغلقة والمفتوحة:

أولاً: تحليل إجابات سكان المنطقة:

- تم تحليل إجابات أفراد العينـة لسكان المنطقة على السؤل السوال التالي: "هل تعاني المنطقة من أي مشكلات؟"، كسؤال ذو نهاية مغلقة فكانت

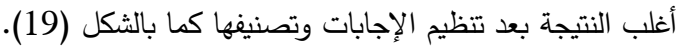

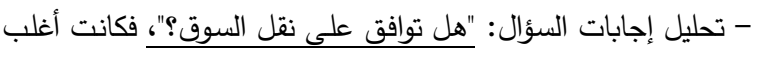
الإجابات من عينة سكان المنطقة نعم وذلك بسبب المشكلات العديدة

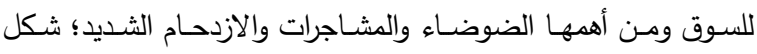

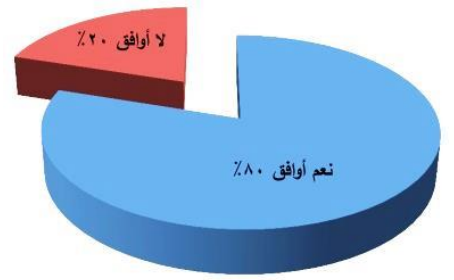

شكل (19) النسب الإحصائية للمشكلات ونقل السوق من وجهة نظر السكان.

- تحليل إجابات عينة الباعة على سؤال آخر وهو : "هل توافق على لـي

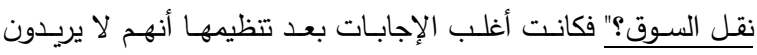

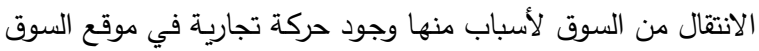

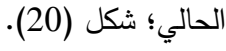

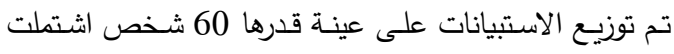
على كافة أنماط الباعة والمشترين وسكان المنطقة وبعض المسئولين بالحي، ويتكون هيكل الاستبيان من ثلاثة أجزاء ويعتبر الجزء الأول خلفية عامة عن أفراد العينة، ويساعد هذا الجزء في تجميع معلومات

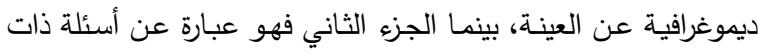
نهايات مغلقة فهي مباشرة وذلك للتوجيه وتفادي الغموض لفهم أنماط البائعين ومعرفة احتياجاتهم، وقد تم تحليل البيانات والمعلومات التي تم الحصول عليها من أفراد العينة، أما الجزه الثالث والأخير هو عبارة عن أسئلة ذات نهايـات مفتوحة وصـمدت هذه الأسئلة بحيث تكون عامة بهدف ترك الأفراد يعبروا عن مشكلاتهم والسبب وراء حضورهم

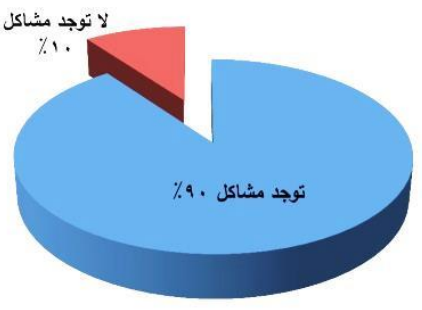
- تم تحليل إجابات أفراد العينة للباعة على السؤال: "متى أتيت للعمل

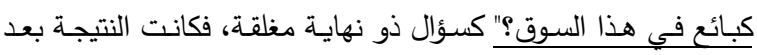
تنظيم الإجابات وحصرها أن الفئة الغالبة في السوق تعمل بهابه به منذ أكثر من 10 سنوات؛ مما يعني ارتباط الباعة بمكان السوق؛ شكل (20). 

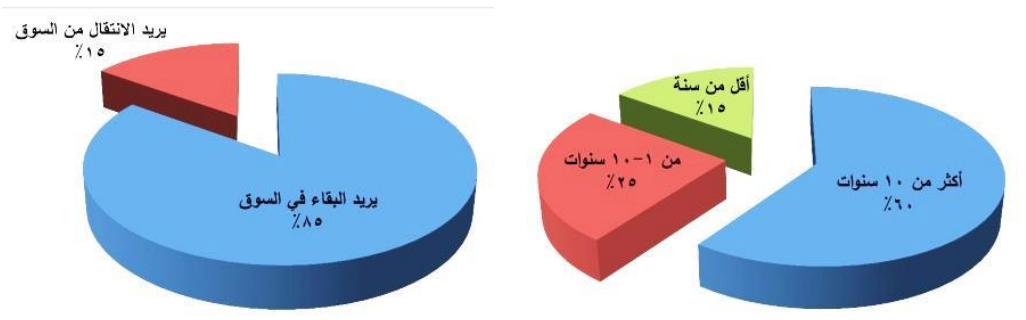

شكل (20) النسب الإحصائية لمدة وجود الباعة في السوق وآرائهم في نقل السوق.

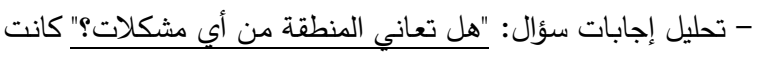
أغلب الإجابات بنعم، ومن هذه المشكلات من وجهة نظر المتسوقين

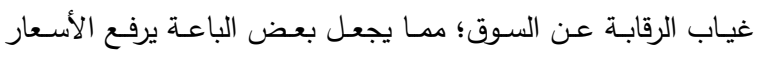

وأيضاً سوء الأخلاق وتنني السلوك للى بعض الباعة الباعة شكل (21).

ثالثاً: تحليل إجابات المتسوقين: - تحليل إجابات سؤال: "ما رأيك في مكان السوق في وضعابه الحالي؟"

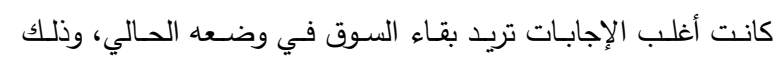

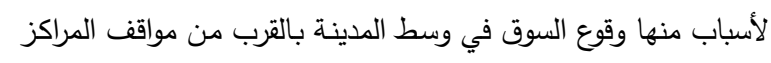

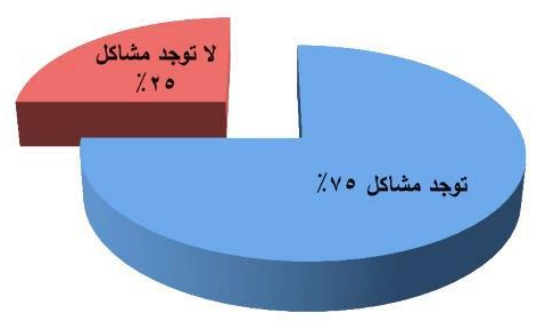

ومحطات المواصلات العامة؛ شكل (21).

شكل (21) النسب الإحصائية لنقل السوق والمشكلات من وجهة نظر المتسوقين.

إلى المكان الجديد ثم يعودوا بعد فترة قصيرة إلى مكانهم القديم، فهناك علاقة قوية بين الباعة والمكان منذ عشرات السنين. يمكن تمويل مشروع تطوير السوق من خـلال صندوق تطوير المناطق العشوائية التابع لمحافظة المنيا، وتأجير الوحدات للباعة بأجر فئرون يتناسب مع امكانياتهج، وذلك نظير إمداد الوحدات بالكهرباء والمياه. ويجب تكليف لجنة من قبل المحافظة بالإشراف على السوق لمتابعة إملاء وضبط المخالفين وتوقيع العقوبات القانونية، وأيضـاً عقد ندوات تثقيفية

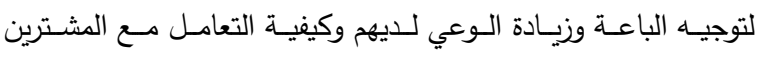

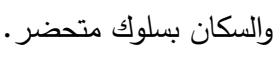
تعتمد فكرة تطوير السوق المفتوح الرئيسي (سوق الحبثي) المقترحة على تطبيق القواعد الأساسية لتخطيط السوق، من فصل حركة المشاه

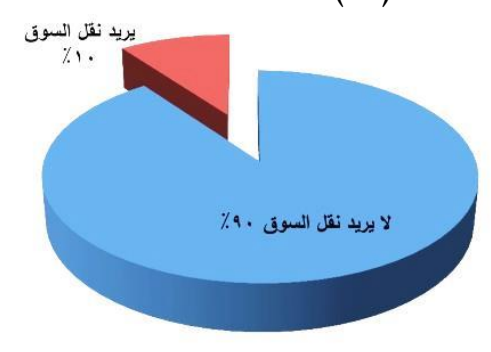

4-3- مشكلات سوق الحبثي: الأسواق المفتوحـة لها مميزات ولا يمكن الاستغناء عنها ولكن تحتاج

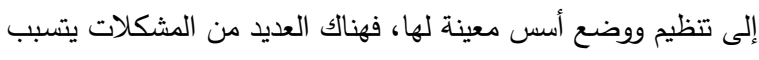
بها السوق العشوائي منها: 1. التلوث البيئي. 2. التلوث السمعي. 3. عرقلة حركة المشاة والاختناق المروري. 4. غياب الخصوصية وغلق المداخل. 5. 5. 5 الانتشار والتشعب. 6. مكاناً خصباً لاندلاع الحرائق.

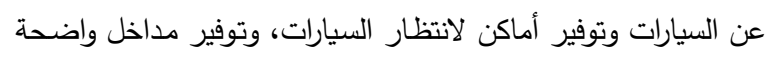

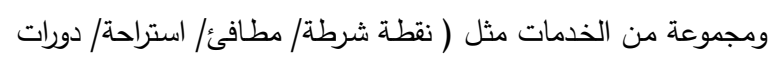

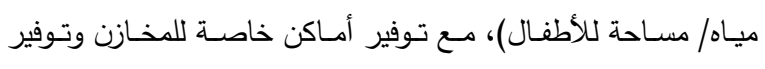

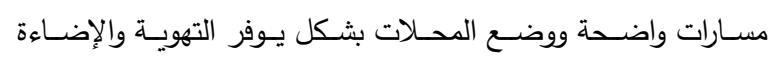
الطبيعية الجيدة.

\section{5- مقترح تطوير سوق الحبشي:}

توصي الدراسة البحثية لسوق الحبشي بمدينة المنيا بعد عمل

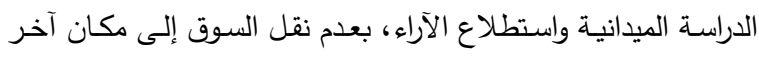

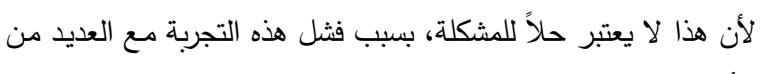
الأسواق العشوائية بمحافظـات الجمهوريـة، حيث يقوم الباعة بالانتقال 


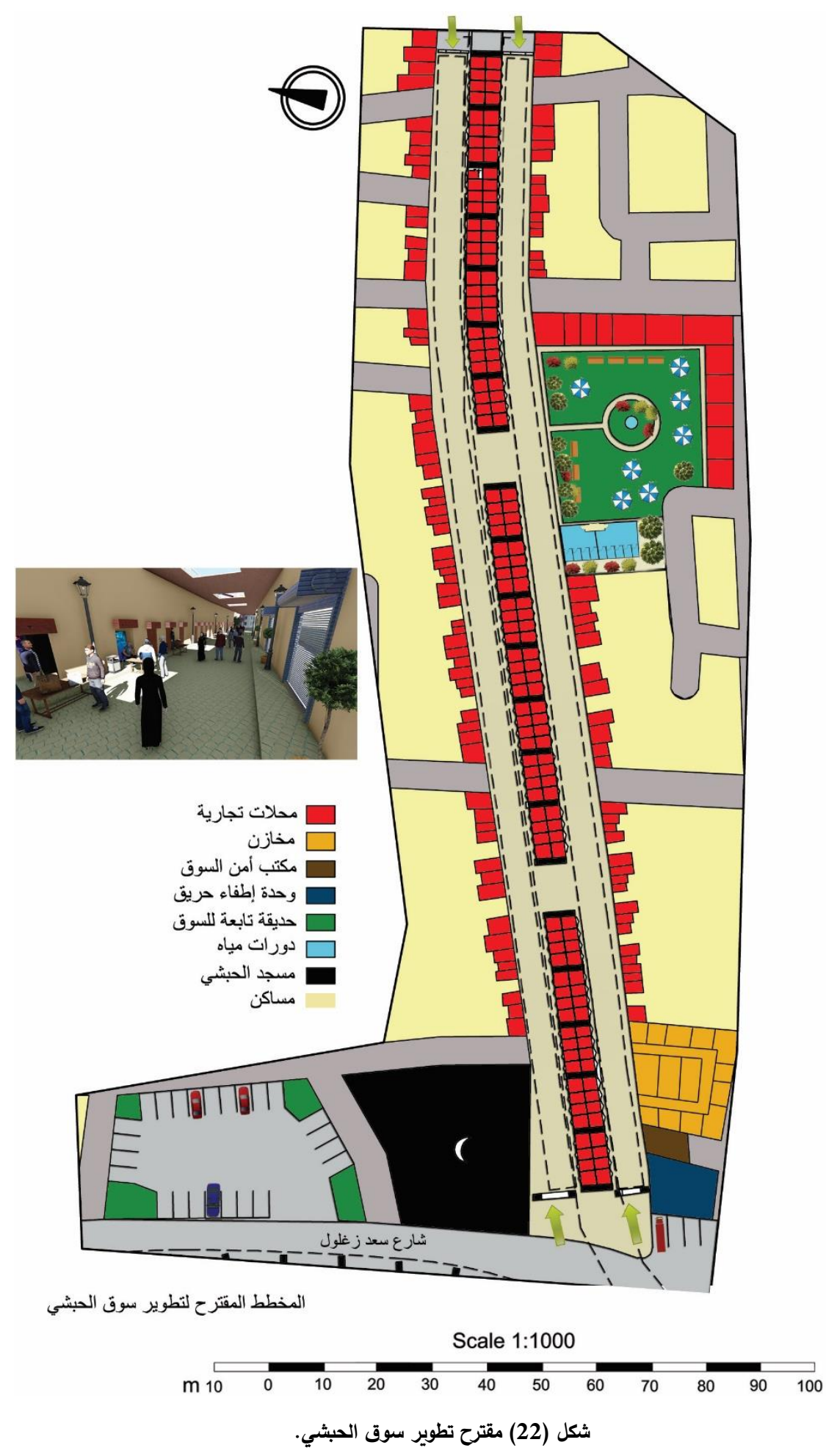

2- الهـدف مـن عمليـة التصـميم العمرانـي للفراغـات يتضـمن تحقيـق 6- النتائج العامة:

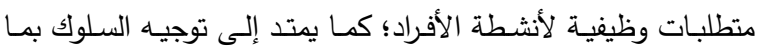

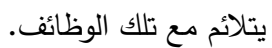

3- احتياجات الإنسان الأساسية من المؤثرات الأساسية على السلوك

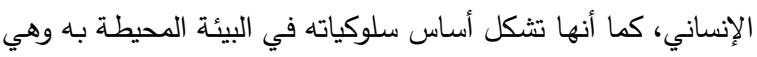

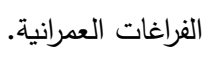

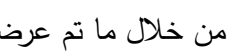
النتائج على النحو التالي:أ- - نتائج مستخلصة من الدراسة النظربة:-

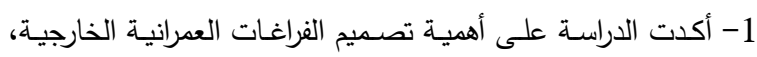
حيث أنها تقترن اقتراناً مباشراً بالإنسان واحتياجاته؛ لأنه هو المستخدم الماته

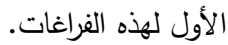


2- هناك ارتباط وثيق ودائم بين السوق العشوائي ومناطق الإسكان العشوائي ذات الدخول المنخفضة والمتوسطة.

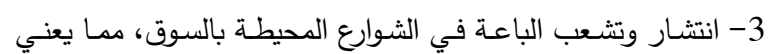
زيادة نطاق تخديم السوق على المدى البعيد.

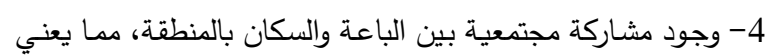
أن هناك نسبة من السكان لا تتضر من وجود السوق. 7 - التوصيات: مـن خـلال مـا تم عرضــه مـن تحليـل وخلاصـة توصـل البحـث إلىى

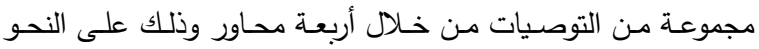

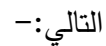
أ- القوانين والتشريعات. - التخطيط.

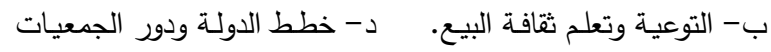
غير الحكومية. أ- القوانين والتشريعات: تتمثـل أهــم التوصـيات في تفعيـل القـانون لتنظـيم العهـل بالأســواق ومواجهـة ظـاهرة الباعـة الجـائلين والأسـواق العشـوائية في إتخـاذ مـن

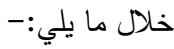
1- إعطـاء الباعـة وضـــاً قانونيـاً بضــــان التـراخيص لهـم وتحقيـق الحماية الاجتماعية، وتوفير التأمين الاجتماعي والصحي لهم.

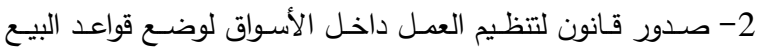

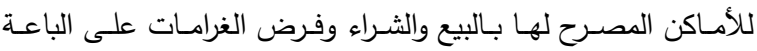

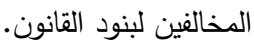
3- تكثيف ومداومة الحملات التفتيثية على مواقع الأسواق العشوائية

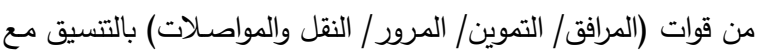

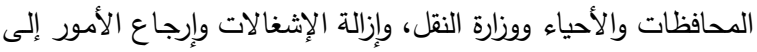
أصلها. 4- الاستعانة بالتقنيات الحديثة ككاميرات المراقبة لمعاونة رجال الأمن للحفاظ على الحالة الأمنية والنظام.

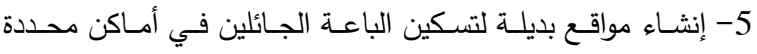

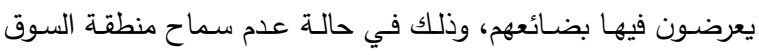

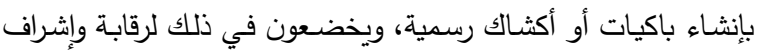

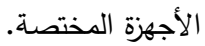

ب- التوعية وتعلم ثقافة البيع:

1- ضرورة تبني خطة إعلامية أمنية لتعريف المواطنين بحق المواطن في تواجد أسواق آمنة، وتحت إشراف الدولة والفرق بينها وبين الأسواق إقليه العشوائية وضررها على المواطن. 2- التعريف بدور الثرطة وأجهزتها المختلفة والتي تعدل في مجال مواجهة ظاهرة الباعة الجائلين والأسواق العشوائية، وأهمية دورها في تحقيق الأمن وانضباط الثـارع المصري عن طريق ضبط المخالفين

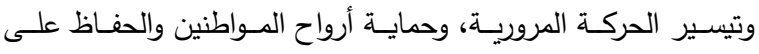
الصحة العامة لهم.
4- الدراسة تؤكد وجود علاقة مزدوجة بين مجال علم النفس البيئي

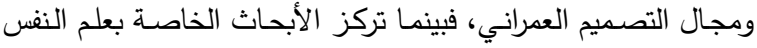

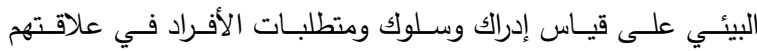
بخصائص البيئة المبنية، فإن المصدم العمراني يحتاج إلى نتائج هذه الأبحاث والدراسات 1 ب- نتائج مستخلصة من الدراسات التطبيقية:-

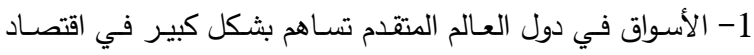
الدولة، ليس فقط لوجود حركة تجارية بها ولكن لكونها أيضـاً ذات قيمة سياحية وتاريخية كبيرة. 2- تتيح الأسـواق في تلك الـدول للزوار أو المشترين تجربـة فريدة وممتعة، من خـلال توفير أنشطة ترفيهية وفراغات مفتوحة كالحدائق

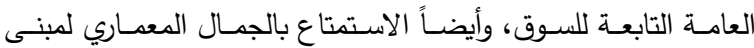

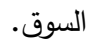
3- تتوفر في الأسـواق جميع الخـمات اللازمـة للبائعين والمشترين كدورات المياة ومكاتب الأمن والإدارة ومواقف انتظعار السيارات.

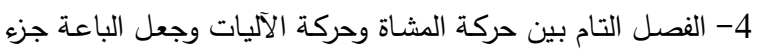
من سياسات أوسع تستهدف تحسين مستويات معيشتهم. ج- نتائج مستخلصة من الدراسة التطبيقية المحلية:1- يوجــ نمـاذج عريقـة للأسـواق فـي مصــر ذات قيمـة سـياحية واقتصادية كبيرة ولكن أصبح بعضها يعاني من الإهمال وغياب أعمال الترميم والتطوير . 2- زيـادة انتثــار المسـطحات التجاريـة أسـفل المبـاني في الثـوارع

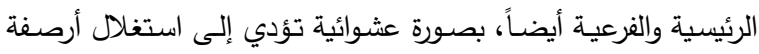
المشاة وتعطيل حركة المرور •

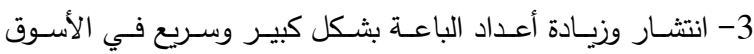
العشوائية، بسبب سهولة الدخول في هذه التجارة، ولأسباب كثيرة منها

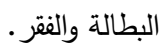
4- تعـاني الدولـة إلى وقتتـا هـذا مـن مشكلة الأسـواق العشـوائية في ولي

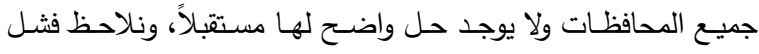
تجربـة نقل السوق إلى مكان آخر في أكثر من مرة بسبب الارتباط القوي بين الباعة والمكان.

د- نتائج مستخلصة من الدراسة الميدانية:1- الفراغات العمرانية أسفل الكباري في مصر تعتبر مكوناً هاماً من

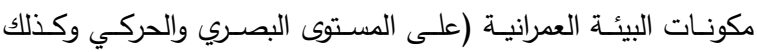
الفراغي)، وتختلف الأنشطة الحادثة في الفراغ أسفل الكباري وتتتوع طبقاً لتنوع ممارسي النشاط من حيث مستوى التعليم أو الدخل ولكن يتطلب ذلك دراسة محاور الحركة وطرق المشاة المتاحة وعلاقة هذه الأماكن بما حولها من مباني سكنية وعامة.

1_ Lang, J "Fundamental Processes of Environmental Behavior "- In John Lang,et al.(Eds), Designing for human behavior: Architecture and the behavioral sciences Stoudsbury: Dowden, Hutchinson \& Ross,Inc- 1974 . 
References: -

1- "Program for the Development and Rehabilitation of Popular Markets in the Kingdom of Saudi Arabia”, General Authority for Tourism and Antiquities, Riyadh, 2016.

2- Hassan Fathy, "The Architecture of the Poor, An Experience in the Countryside of Egypt", translated by Mustafa Ibrahim, The Publications of Today's Book, Issue 6, 1991, p.81.

3- Hassan Fathy "The Architecture of the Poor", Egyptian Book Authority, 2001.

4- "The Public Market Planning Guide", Ministry of Municipal and Rural Affairs, Riyadh, 2005.

5- Rasha Abdel-Rahman Mohamed, "The Impact of Design Considerations and Standards for Urban Spaces on Human Needs," Master Thesis, Faculty of Engineering, Cairo University, 2010.

6- Suheir Essam Ibrahim, "Strategies for Sustaining Traditional Commercial Streets: A Case Study of Khan Al-Trajan in Nablus," Master Thesis, College of Graduate Studies, An-Najah National University, Palestine, 2008.

7- Sayed Al-Touni, "Urban Design in Concept and Importance", Journal of the Department of Architecture, Book Five, Cairo, 1990.

8- The Informal Settlements Development Fund, http://www.isdf.gov.eg.

9- Abd al-Fattah Ibrahim, "The Meeting”, Dar AlTali’a, Beirut, 1971, p. 130.

10- Alia Al Mahdi and Amira Mashhour, "The Informal Sector in the Maarouf Region," The National Center for Research and Social and Criminal Studies, Cairo, 1994.

11- Zainab Faisal, "The Reality of Traditional Markets in the Contemporary City", The Fifth International Conference at the Faculty of Engineering, Cairo University, 2009.

12- Celik, "Story of the Grand Bazaar", Istanbul, 1980 .

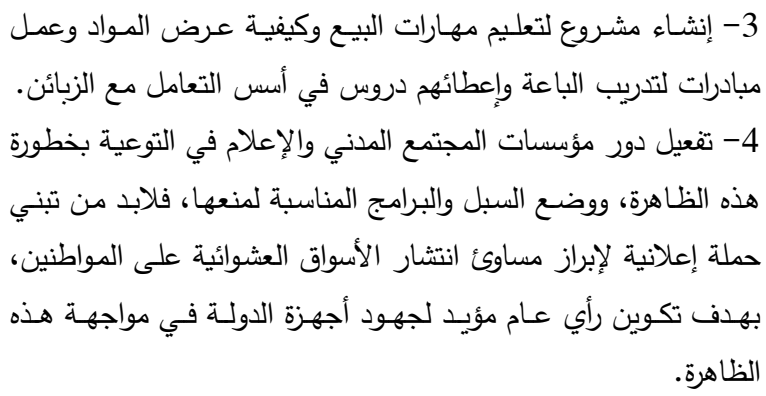


Vol. 39, No. 1. July 2020

13- Curran, R.J.,"Architecture and The Urban Experience". Van Nostrand Reinhold Company, London. 1983. P(24).

14- Forti, "Research \& Human Needs", Augusts and Bisogono, Paoloed, 1981,P (11).

15- Gosling, D.a.M.B., "Concepts of Urban Design". 1984: St, Martin;s press, New York.

16- John Magill, "French Market Celebrates 200th Anniversary", PIP article, the magazine of the preservation center, 1991.

17- Kevin Lynch," THE IMAGE OF THE CITY",the MIT press, Cambridge, London, 1960.

18- Lang, J "Fundamental Processes of Environmental Behavior "- In John Lang,et al.(Eds), Designing for human behavior: Architecture and the behavioral sciences Stoudsbury: Dowden, Hutchinson \& Ross,Inc- 1974.

19- Moore,G.T-"Environment Behavior Studies" .New York.Mac Graw-Hill 1979.

20- Progetto, "La Galleria Vittorio Emanuele di Milano", Ornella Selvafolta, DS Comunicazione, 2016.

21- Pour,M,"Design of Urban Spaces"John Wiley,USA, 1996,P(120).

22- Rapoport,A-“The Meaning Of The Built Environment"- California,Sage Publications- 1982.

23- Rob Krier "URBAN SPACE" ,Academy Edition, Great Britain,1975.

24- Zucker,p, "Town and Square: from the Agora the village Green", 1973.

25- www.frenchmarket.org/history.

26- http://aviewoncities.com

27- http://greatbuildings.co 
Vol. 39, No. 1. January 2020 